Milesi García, L., Aranda Jiménez, G., Sánchez Romero, M., López Sáez, J. A., Pérez Díaz, S., Fernández Martín, S., Martínez-Sevilla, F. y Díaz-Zorita Bonilla, M. (2020): “El recinto de fosos calcolítico del Cerro de los Vientos (Puente del Obispo, Jaén)", Spal 29.2: 11-30. DOI: https://dx.doi.org/10.12795/spal.2020.i29.15

\title{
EL RECINTO DE FOSOS CALCOLÍTICO DEL CERRO DE LOS VIENTOS (PUENTE DEL OBISPO, JAÉN)
}

\section{THE CHALCOLITHIC DITCHED ENCLOSURE OF CERRO DE LOS VIENTOS (PUENTE DEL OBISPO, JAEN)}

\author{
LARA MILESI GARCÍA \\ Responsable de la correspondencia \\ Universidad de Málaga, Facultad de Filosofía y Letras, Dpto. Ciencias Históricas, Campus Teatinos, s/n. 29071 Málaga. \\ Correo-e: Imilesi@uma.es, responsable de correspondencia (D) https://orcid.org/0000-0001-9002-015X \\ ResearcherID: https://publons.com/researcher/S-2548-2019 \\ GONZALO ARANDA JIMÉNEZ \\ Universidad de Granada, Facultad de Filosofía y Letras, Dpto. Prehistoria y Arqueología, Campus Cartuja, s/n, 18011 Granada. \\ Correo-e: garanda@ugr.es D https://orcid.org/0000-0003-1925-0221 \\ ResearcherID: https://publons.com/researcher/K-8857-2017 \\ MARGARITA SÁNCHEZ ROMERO \\ Universidad de Granada, Facultad de Filosofía y Letras, Dpto. Prehistoria y Arqueología, Campus Cartuja, s/n, 18011 Granada. \\ Correo-e: marsanch@ugr.es (D) https://orcid.org/0000-0002-3489-9195 \\ ResearcherID: https://publons.com/researcher/K-8879-2017 \\ JOSÉ ANTONIO LÓPEZ SÁEZ \\ Instituto de Historia, Centro de Ciencias Humanas y Sociales, CSIC, c/Albasanz, 26-28, 28037 Madrid. \\ Correo-e: joseantonio.lopez@cchs.csic.es D https://orcid.org/0000-0002-3122-2744 \\ ResearcherID: https://publons.com/researcher/M-7683-2014 \\ SEBASTIÁN PÉREZ DÍAZ \\ Universidad de Cantabria. Depto. de Geografía, Urbanismo y Ordenación del Territorio. \\ ETS Caminos, Canales y Puertos. Avda. de los Castros, s/n. 39005. Santander. \\ Correo-e: sebastian.perezdiaz@unican.es D https://orcid.org/0000-0002-2702-0058 \\ ResearcherID: https://publons.com/researcher/AAB-3124-2019) \\ SERGIO FERNÁNDEZ MARTÍN \\ Universidad de Granada, Facultad de Filosofía y Letras, Dpto. Prehistoria y Arqueología, Campus Cartuja, s/n, 18011 Granada. \\ Correo-e: sfcalar@yahoo.es (D) https://orcid.org/0000-0003-1099-2640 \\ ResearcherID: https://publons.com/researcher/AAH-1873-2019 \\ FRANCISCO MARTÍNEZ-SEVILLA \\ Universidad de Granada, Facultad de Filosofía y Letras, Dpto. Prehistoria y Arqueología, Campus Cartuja, s/n, 18011 Granada. \\ Correo-e: martinezsevilla@ugr.es (D) https://orcid.org/0000-0002-1385-3585 \\ ResearcherID: https://publons.com/researcher/AAH-3906-2019

\section{MARTA DIAZ-ZORITA BONILLA} \\ University of Tübingen SFB 1070 “Ressourcenkulturen”, Tübingen University, Gartenstrasse 29, 72074, Tübingen (Alemania). \\ Correo-e: marta.diaz.zorita-bonilla@uni-tuebingen.de (D) https://orcid.org/0000-0002-1697-0111 \\ ResearcherID: https://publons.com/researcher/AAH-1209-2019
}


Resumen: En este trabajo se da a conocer el recinto de fosos prehistórico del Cerro de los Vientos, localizado en la población de Puente del Obispo (Jaén, España). Se presentan su planta completa, las estructuras que lo componen, la caracterización de los conjuntos cerámicos y líticos hallados en sus rellenos, dos dataciones inéditas y el análisis polínico realizado en el yacimiento. Estos estudios han permitido reconocer la construcción de dos fosos concéntricos y más de noventa fosas circulares realizadas durante la Edad del Cobre. Un espacio de ocupación que, además, experimentará la construcción de nuevas estructuras en negativo, algunas construcciones en mampostería y la completa amortización de su foso central durante la Edad del Bronce.

Palabras claves: recinto de fosos; cronología; cerámica; útiles macrolíticos; datos polínicos.

\section{INTRODUCCIÓN}

El estudio de los recintos de fosos de la Prehistoria Reciente del sur peninsular ha vivido grandes avances durante las dos últimas décadas (Jiménez-Jáimez 2015). El comienzo de su debate teórico (Márquez Romero 2001, Márquez Romero 2002, Delibes de Castro 2001, Márquez Romero y Jiménez Jáimez 2010) y el reclamo de mejores métodos de estudio para los mismos (Díazdel-Río 2003: 74-75) favorecieron el reconocimiento y estudio de un mayor número de este tipo de yacimientos. Desde principios de los años 90 hasta nuestros días, los recintos conocidos como tales han pasado de algo más de una decena a más de ochenta (Jiménez-Jáimez 2015, Blasco et al. 2007, García García 2013, Martínez Calvo et al. 2014, Delibes de Castro et al. 2014, Escudero Carrillo et al. 2017, entre otros). La incorporación de nuevas técnicas de detección, como la prospección geomagnética o teledetección, y la incorporación de estudios isotópicos han permitido su mejor caracterización cronológica, constructiva $\mathrm{y}$, en definitiva, de las sociedades prehistóricas vinculadas a este tipo de sitios (Balsera et al. 2015, Aranda Jiménez et al. 2016, García Sanjuán et al. 2018, Díaz-Zorita Bonilla et al. 2018, 2020; Žalaité et al. 2018, Milesi et al. 2019, entre otros).

En el sur de la península ibérica el fenómeno de los recintos de fosos encuentra sus primeras fases constructivas ya a finales del IV milenio cal BC. Este tipo de arquitectura presenta especial auge durante la segunda mitad del III milenio cal BC, período en el que existe una mayor intensidad constructiva, aparición de los fosos más grandes y de los mayores aportes de relleno (Márquez Romero y Jiménez Jáimez 2013: 455, Milesi et al. 2019: 174).
Abstract: This paper presents the prehistoric ditched enclosure of Cerro de los Vientos located in Puente del Obispo (Jaén, Spain). The study has made possible the characterization of the site, including its complete layout, main architectural features, two unpublished radiocarbon dates, and the pottery, lithic, and pollen analyses. The site consists of two concentric circular ditches and more than ninety pits built during the Copper Age. In addition, new structures, masonry constructions and the final infilling of the central ditch were carried out in the Bronze Age.

Keywords: ditched enclosure; chronology; pottery; macroliths; pollen data.

Sus características principales son la existencia de uno o varios fosos de tendencia circular, dispuestos de forma concéntrica, llegando en algunos casos a la existencia de más de una decena de fosos, como es el caso de Perdigões (Reguengos de Monsaraz) en Portugal (Márquez Romero et al. 2011). Normalmente, los fosos presentan una o varias interrupciones interpretadas como zonas de paso o puertas. Junto a estas grandes estructuras aparecen también numerosas fosas excavadas en el sustrato geológico con diferentes formas y tamaños. En la mayoría de los casos es patente la superposición de construcciones (fosas, fosos, zanjas), solapándose unas sobre otras e indicando un uso reiterado del espacio a lo largo del tiempo, aunque no necesariamente continuo.

Todas las estructuras aparecen rellenadas con diversos aportes sedimentarios naturales y antropogénicos, que normalmente presentan restos líticos, cerámicos y óseos que habitualmente aparecen fragmentados y mezclados sin un aparente orden. La presencia de restos metálicos suele ser limitada. Buenos ejemplos peninsulares de este tipo de yacimiento son Valencina de la Concepción (Fernández Gómez y Oliva Alonso 1986), La Pijotilla (Hurtado 1986), Perdigões (Lago et al. 1998), Porto Torrão (Valera y Filipe 2004) o Loma del Real Tesoro (Escudero Carrilllo et al. 2017), entre otros muchos.

En la provincia de Jaén se conocen al menos tres casos que responden a estas características, son los yacimientos de Martos (Lizcano et al. 1993), Venta del Rapa (Lechuga Chica et al. 2014) y Marroquíes Bajos (Zafra de la Torre et al. 1999). A menos de $50 \mathrm{~km}$ de distancia de estos se localizó el recinto de fosos del Cerro de los Vientos, en las cercanías de la población de Puente del Obispo. Su hallazgo se produjo a partir de 


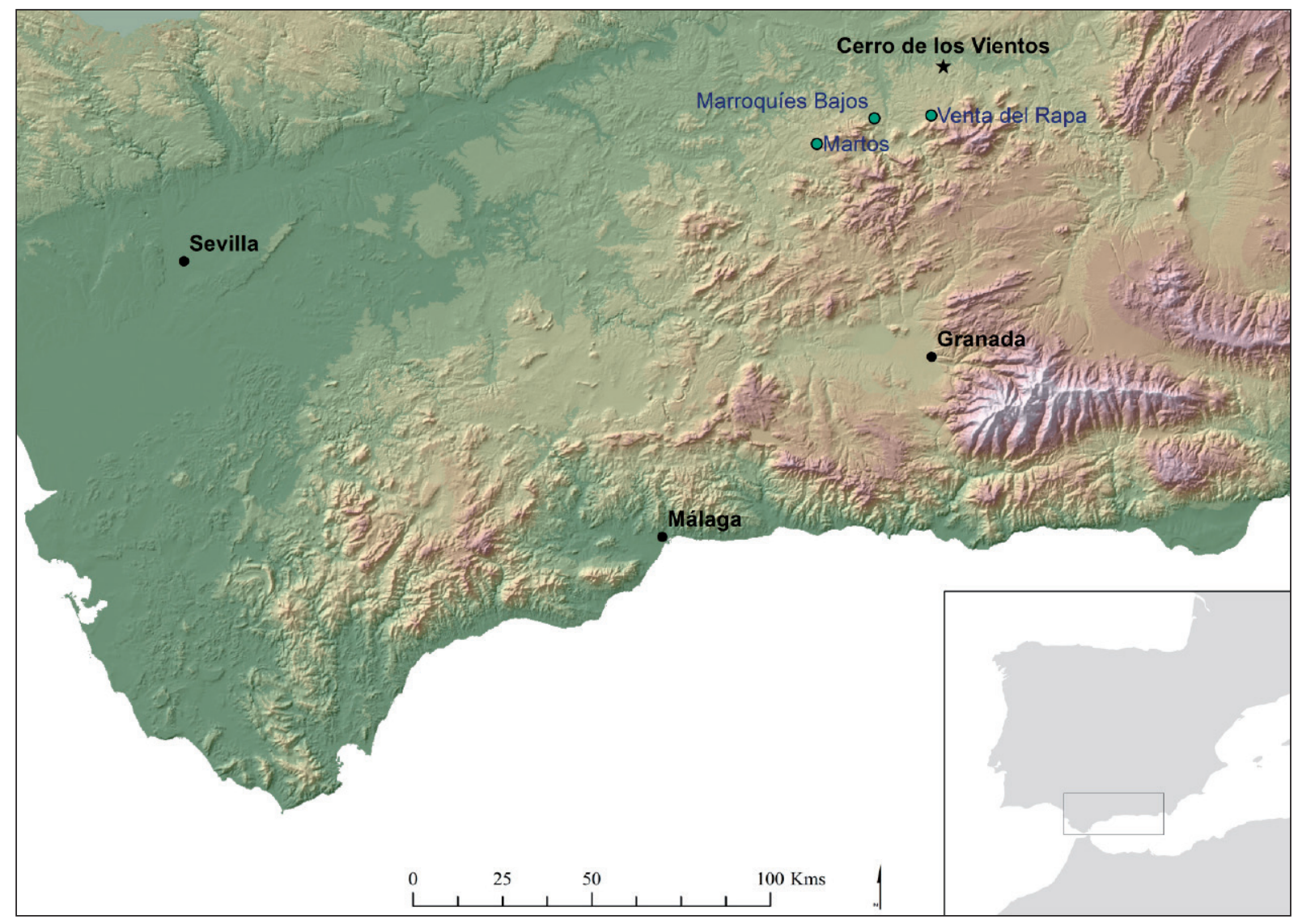

Figura 1. Localización del yacimiento del Cerro de los Vientos en el sur peninsular. Las localizaciones cercanas corresponden a otros recintos de fosos de la región (en verde).

las actuaciones preventivas realizadas por la construcción de la autovía A-316 en el tramo "Enlace Norte-Enlace Sur de Puente del Obispo". El yacimiento se ubica en la zona superior del cerro homónimo, a unos $375 \mathrm{~m}$ de altitud, en el valle del río Guadalquivir y junto al río Torres (fig. 1).

La primera fase de las excavaciones se realizó entre los años 2009 y 2011 por el Centro Andaluz de Arqueología Ibérica. La segunda etapa fue llevada a cabo por Gespad Al-Andalus s.l.u., durante los años 2014 y 2015. Ambas intervenciones consistieron en excavaciones en extensión y permitieron caracterizar los principales rasgos del yacimiento en toda su superficie.

Con el objetivo de un mayor conocimiento del yacimiento, se unificaron las planimetrías y descripciones generadas en las distintas intervenciones y se analizaron los materiales arqueológicos de la segunda etapa de excavación (2014-2015). A continuación se presentan sus resultados.

\section{MORFOLOGÍA DEL YACIMIENTO DEL CERRO DE LOS VIENTOS}

Al igual que ocurre en otros recintos de fosos, el yacimiento presenta numerosas estructuras prehistóricas excavadas en el sustrato geológico, en este caso constituido principalmente por margas. Entre estas destacan dos fosos circulares concéntricos y casi un centenar de fosas de tendencia circular. También se caracterizaron otras estructuras de formas más irregulares y en ocasiones realizadas en mampostería. El acceso a los dos recintos consiste en dos interrupciones en el trazado de los fosos que aparecen alineadas y orientadas hacia el este (fig. 2).

\subsection{Foso interior}

La estructura FS-8011 presenta un diámetro medio de $20 \mathrm{~m}$ y ocupa la parte central del yacimiento. Este recinto abarca un área aproximada de $315 \mathrm{~m}^{2}$. Posee un 


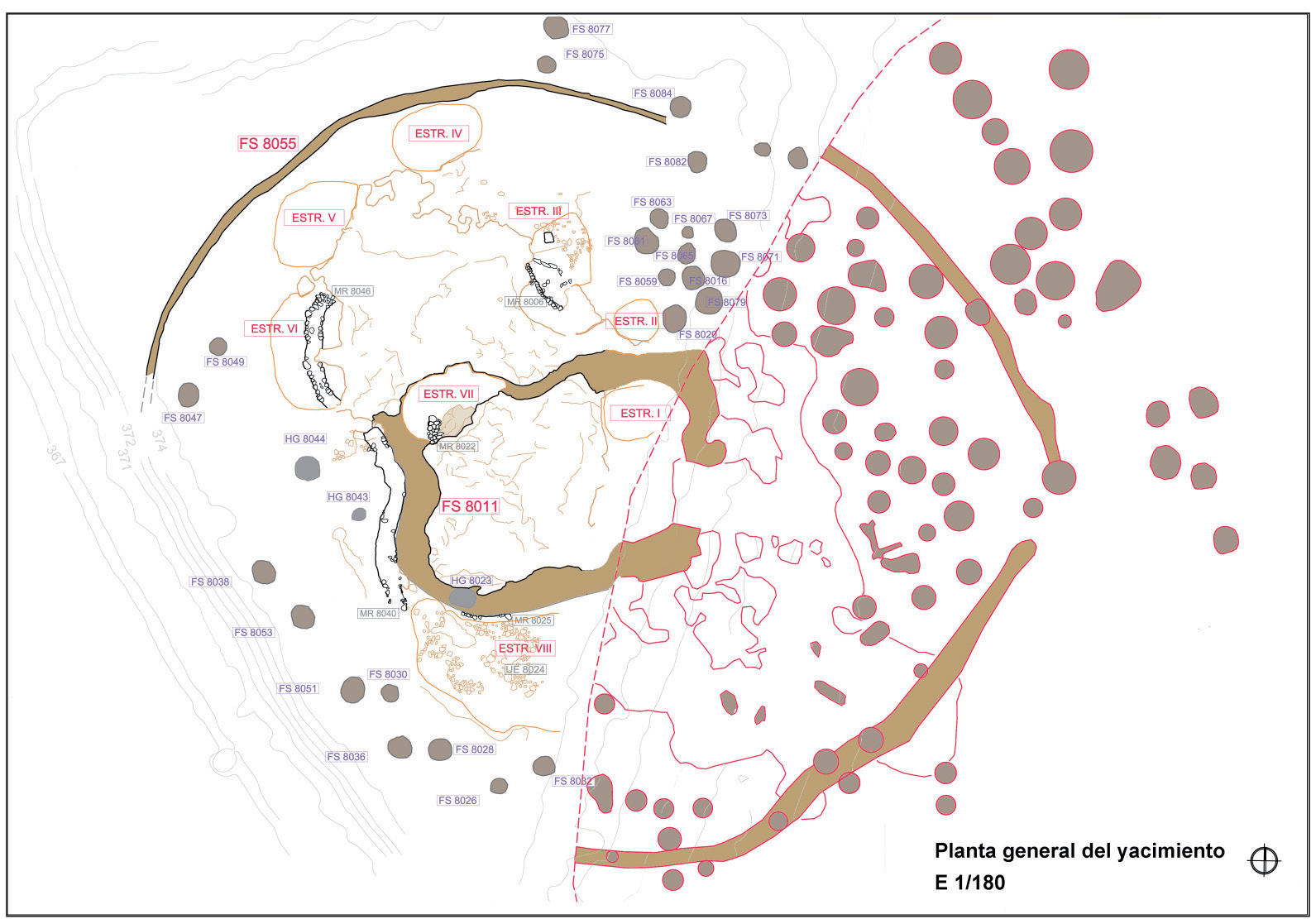

Figura 2. Planta del yacimiento. La línea discontinua separa las campañas de excavación: derecha sector excavado en 2009-11, izquierda sector excavado entre 2014-15. En negro, se señala la localización de las secciones. (Modificado a partir de la planta de 2014-2015).

recorrido polilobulado y sección en $\mathrm{V}$. Su ancho oscila entre 0.5 y $3.5 \mathrm{~m}$ y su profundidad entre 1.8 y $2.4 \mathrm{~m}$. El único acceso al recinto se orienta hacia el este.

En este foso se conocen tres secciones en las que se pudo caracterizar la estratigrafía del relleno (fig. 3). Este presenta un primer estrato sedimentario marrón claro, con matriz limo-arenosa (UE8124) que se documenta en todos los sectores de excavación. Los depósitos intermedios poseen una matriz limo-arcillosa y se disponen con mayor tendencia a la horizontalidad, aunque pueden alternarse con algunos estratos con mayor buzamiento.

Todos los estratos presentan diferentes concentraciones de fragmentos cerámicos y líticos, cuya clasificación tipológica los situaría en época calcolítica. En algunos casos, se evidencia también la presencia de cenizas. Los restos de fauna son escasos en este sector, solo se registró un fragmento en la UE 8122 del corte B.

El depósito sedimentario más reciente que se encuentra en el total del recorrido del foso (UE 8012) se caracteriza por una matriz limo-arcillosa, marrón oscura, con inclusiones líticas de tamaño medio y pequeño, fragmentos cerámicos y escasos restos óseos, cuyas características y datación corresponden a la Edad del Bronce.

La estratigrafía parece indicar que el foso se habría ido colmatando con diversos aportes de carácter antropogénico, siendo el depósito más reciente de la Edad del Bronce.

Durante este último período, se practicaron algunas modificaciones que afectaron a parte del relleno del foso y de su trazado. Estas modificaciones consistieron en la construcción de dos estructuras negativas (ESTRVII y ESTR-VIII) y dos construcciones en mampostería, una asociada al límite exterior del foso (MR-8040) y otra afectando parte de su trazado interior (MR-8022).

\subsection{Foso exterior}

El foso exterior (FS-8055) presenta aproximadamente unos $25 \mathrm{~m}$ de diámetro y engloba un área de cerca 
de $500 \mathrm{~m}^{2}$. Cuatro secciones fueron excavadas en este foso. Su anchura oscila entre 0.4 y $1.5 \mathrm{~m}$ y su potencia alcanza un máximo de $1.1 \mathrm{~m}$ y un mínimo de $0.45 \mathrm{~m}$. Su sección es también en V (fig. 4). De acuerdo con su morfología y sus dimensiones, se ha propuesto como un foso para una posible empalizada, si bien no se cuenta con restos materiales que así lo evidencien. Las discontinuidades que se aprecian al norte y sur del foso se deben a su destrucción parcial debido a las obras relacionadas con la formación de taludes.

Su relleno se componía de diferentes aportes naturales y antropogénicos, en los que se documentaron restos líticos y cerámicos (en las UEs 8056 y 8099). Sus características tipológicas situarían la cronología de este foso en la Edad del Cobre (fig. 4).

$\mathrm{Al}$ igual que en el foso interior, se ha constatado al menos una interrupción en el trazado, que correspondería a la zona de acceso al recinto. Esta puerta está alineada con la del foso interior y cuenta con una anchura de $3 \mathrm{~m}$.

\subsection{Fosas circulares}

Se han documentado 92 fosas localizadas entre ambos recintos, sobre el foso más externo y al exterior de este último. El recinto central delimitado por el foso interno

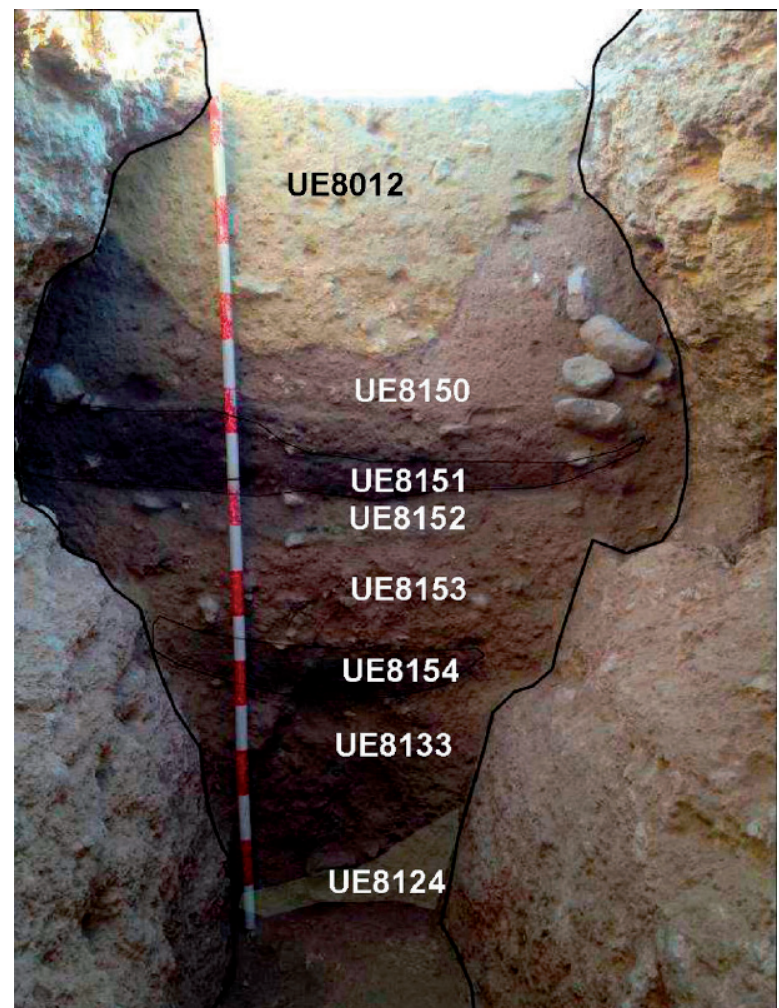

Figura 3. Sección del foso interno con orientación N-S (véanse las localizaciones en figura 2).

Figura 4. Secciones del foso externo. Orientación

$\mathrm{O}-\mathrm{E}$ en secciones $1,2 \mathrm{y}$

4. Orientación N-S en sección 3 (véanse las localizaciones en figura 2).

FS- 8055
Sección 1

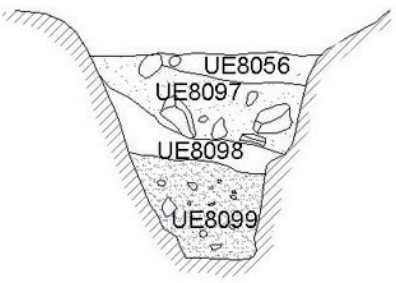

Sección 3

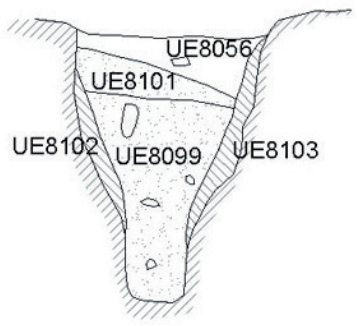

Sección 2

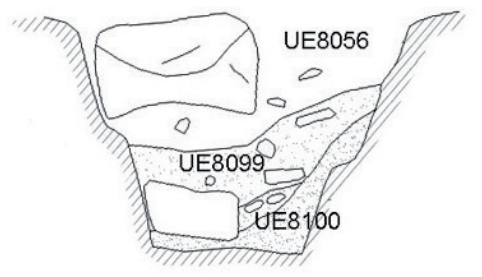

Sección 4

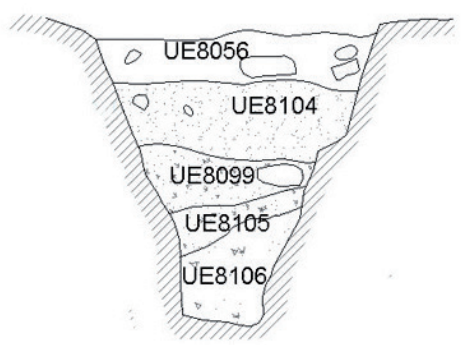

$1 \mathrm{~m}$ 


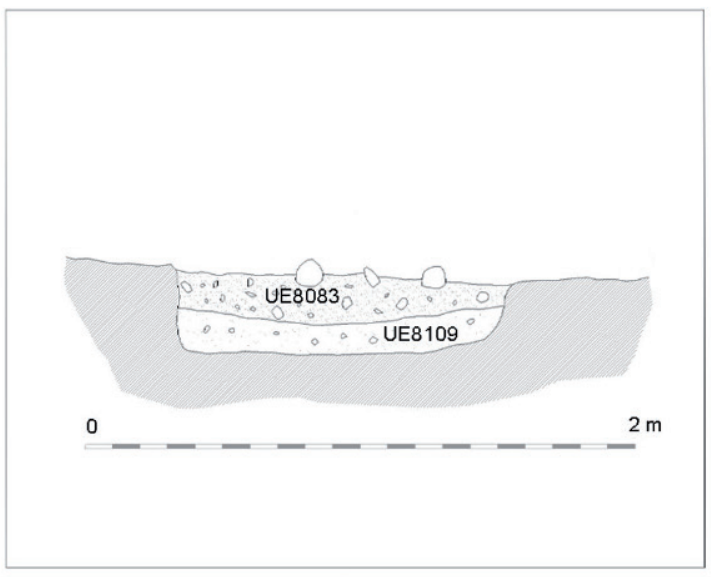

Fosa 8082

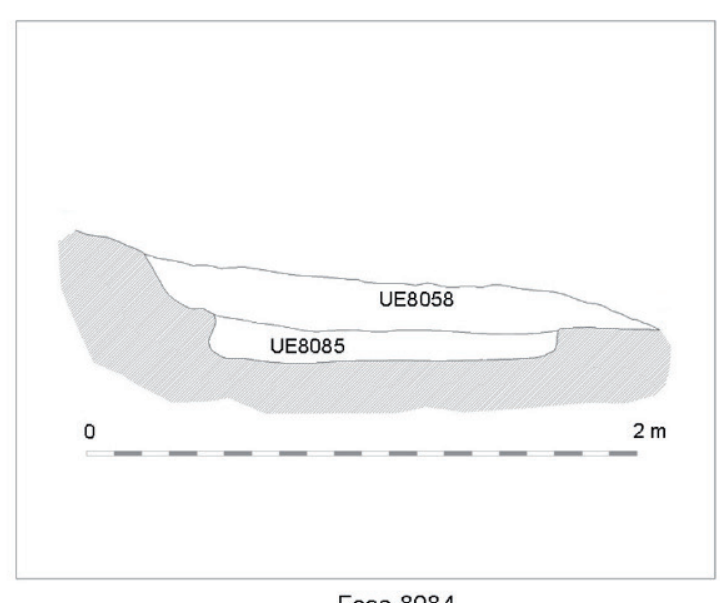

Fosa 8084

Figura 5. Secciones de las fosas 8082 y 8084 con orientación O-E.

y la zona noroeste del segundo recinto no presentaron este tipo de estructuras.

En las intervenciones realizadas entre 2014 y 2015 se excavaron todas las fosas identificadas en planta con un total de 26 (fig. 2). Las dimensiones de estas oscilan entre 0.2 y $1.3 \mathrm{~m}$ de potencia y 0.5 y $2.5 \mathrm{~m}$ de diámetro. Como ocurre en la mayoría de yacimientos con iguales características, las secciones de este tipo de estructuras varían entre paredes rectas y más o menos acampanadas (fig. 5).

$\mathrm{Si}$ bien las formas y dimensiones presentan variaciones, los depósitos interiores presentan unas características similares. En todas ellas se han registrado fragmentos cerámicos, algunos restos líticos y escasos o nulos restos óseos, distribuidos en los diferentes estratos. La mayoría de las formas cerámicas recuperadas en estas estructuras se corresponden tipológicamente con las producidas durante el III milenio cal BC.

\subsection{Otras estructuras prehistóricas}

Además de las anteriores construcciones, se documentó la existencia de al menos ocho estructuras de formas irregulares excavadas en la matriz geológica (EST-I a VIII). De acuerdo con las relaciones estratigráficas, estas construcciones habrían sido realizadas con posterioridad a la amortización de los fosos (EST-VII y EST-VIII) o cuando estos estaban siendo colmatados.

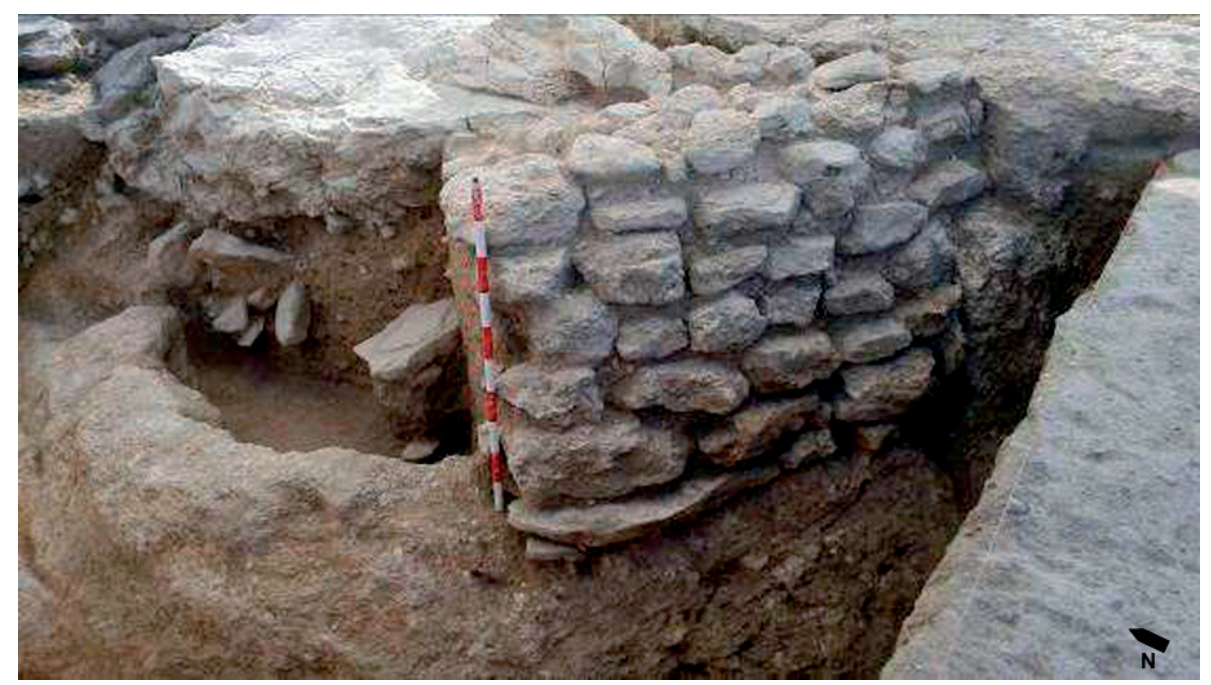

Figura 6. Muro de mampostería asociado a la construcción EST-VII. 
Figura 7. Sección de la estructura EST-III con orientación E-O.

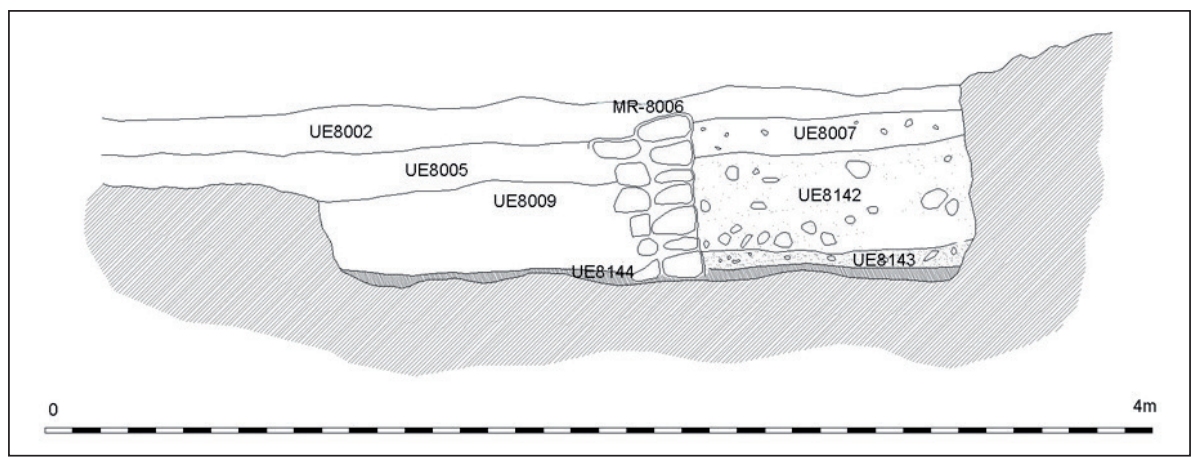

Tres de estas construcciones afectan al foso central (FS-8011). La primera de ellas (EST-I) se localiza en el sector norte del foso. Presenta planta circular de $2.1 \mathrm{~m}$ de diámetro, base plana y una altura de $1 \mathrm{~m}$. La segunda (EST-VII), se ubica en la zona oeste del mismo foso y presenta en su interior la construcción de un muro de mampuestos (MR-8022) (fig. 6), que se adapta al recorrido del foso en un tramo de $2 \mathrm{~m}$ y con $1 \mathrm{~m}$ de altura.

De similar complejidad son las EST-III, VI y VIII. La primera de ellas, de grandes dimensiones $(4.2 \mathrm{~m} \mathrm{de}$ largo y $2 \mathrm{~m}$ de ancho), presenta un muro interno realizado con cantos y adobes de mediano tamaño (MR8006) (fig. 7).

Por su parte, la EST-VI (fig. 8) se caracteriza por su planta ligeramente ovalada, con una longitud de $5.15 \mathrm{~m}$ (N-S) y un ancho de $4.10 \mathrm{~m}$ (E-O). Presenta una construcción tipo covacha y también un muro de mampuestos en su lado oeste (MR-8046).

Finalmente, la estructura EST-VIII tiene una longitud de $5.6 \mathrm{~m}(\mathrm{~N}-\mathrm{S})$, un ancho de $4.5 \mathrm{~m}$ (E-O) y su potencia alcanza un máximo de $0.5 \mathrm{~m}$. También presenta en su interior una construcción de mampostería (MR-8024), cuyos restos podrían relacionarse con la abundante presencia de cantos y mampuestos de tamaño mediano en el relleno de EST-VIII, tal vez correspondientes a su derrumbe parcial.

\section{ESTUDIO DE MATERIALES}

\subsection{Cronología}

La escasa presencia de restos orgánicos limitó el número de muestras para la datación radiocarbónica de los rellenos. Las dataciones que se pudieron realizar corresponden a restos óseos humanos hallados en la última unidad estratigráfica de colmatación del foso interior (UE 8012) y a una unidad de relleno de la EST-VII (UE 8118). Los fragmentos de huesos disponibles pudieron ser caracterizados siguiendo métodos

Figura 8. Fotografía de EST-VI.

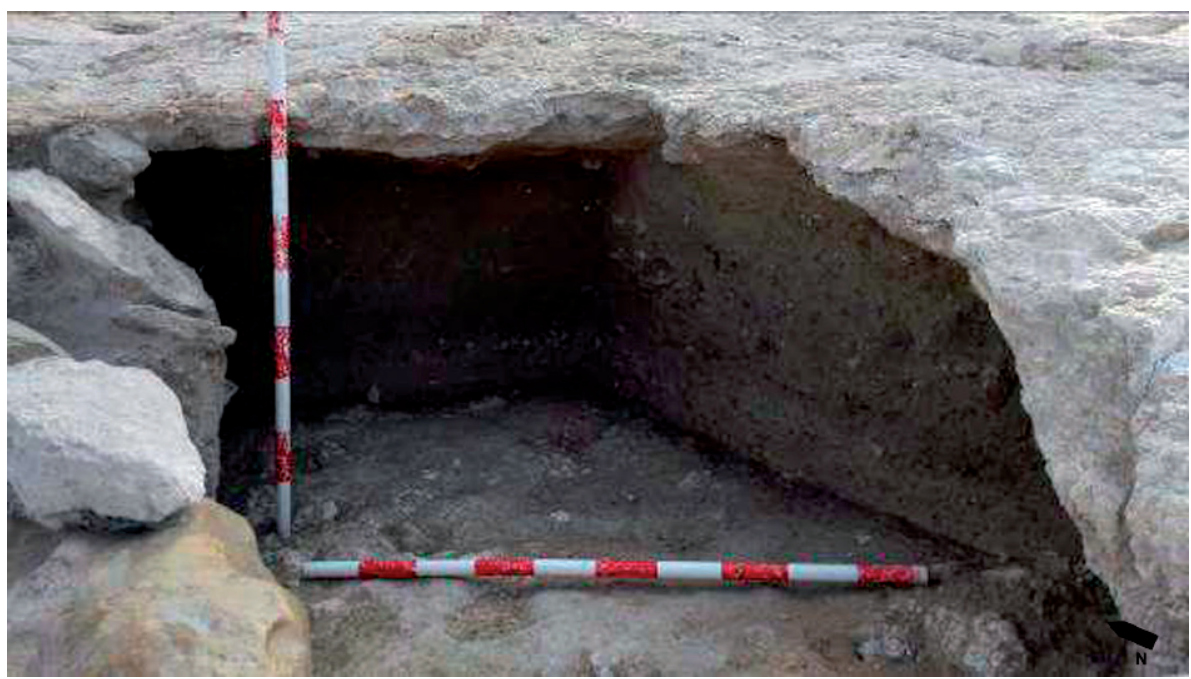


bioarqueológicos estándar, a pesar de su mal estado de conservación. Se identificaron un fragmento de tibia y un fragmento de radio.

Siguiendo la estrategia desarrollada en trabajos previos (Aranda Jiménez et al., 2017, 2018, 2020), la selección de las muestras se realizó a partir del NMI (Número Mínimo de Individuos), de forma que se garantizara la datación de individuos diferentes. De esta forma, se seleccionaron dos muestras pertenecientes a dos individuos de edad adulta. La extracción del colágeno óseo se ha llevado a cabo en el Departamento de Ciencias Geológicas de la Universidad de Tübingen y antes a su extracción se ha realizado un análisis elemental $(\% \mathrm{C} \mathrm{y}$ $\% \mathrm{~N}$ ) como indicador previo de la conservación del colágeno. El protocolo para la extracción del colágeno se basa en métodos estándares (DeNiro y Epstein 1981, Bocherens et al. 1997). Las mediciones radiométricas se realizaron en el laboratorio ETH Zürich, mediante AMS (Accelerator Mass Spectometry). Para conocer el efecto reservorio posible también se han medido los isótopos estables de carbono y nitrógeno $\delta^{13} \mathrm{C}$ y $\delta^{15} \mathrm{~N}$. Las dataciones han sido calibradas con la curva IntCal13 (Reimer et al. 2013) utilizando Oxcal 4.3.2 (Bronk Ramsey 2009) y las fechas han sido redondeadas siguiendo las recomendaciones de Stuiver y Polach (1977).

Ambas dataciones radiocarbónicas (tab. 1) sitúan los restos humanos en el Bronce Tardío (posargárico). La primera de ellas corresponde al relleno de la EST-VII con fechas entre el 1415-1315 cal BC (68\%) y 14301300 cal BC (95\%). La segunda corresponde al último relleno del FS-8011 y sitúa las fechas entre 1430-1325 cal BC (68\%) o 1440-1305 cal BC (95\%). Ambas fechas sitúan la fase más reciente de la ocupación del Cerro de los Vientos en la segunda mitad del II milenio cal BC.

\subsection{Conjuntos cerámicos}

El conjunto cerámico supone un total de 1164 fragmentos, de los cuales 966 son amorfos y 177 son de selección. El estudio de estos últimos ha permitido definir la forma de 157 fragmentos (fig. 9). Los criterios de clasificación y denominación siguen los realizados por Contreras y Cámara (2000), Aranda Jiménez (2001) y Fernández (2005, 2008, 2012, 2015).

El análisis más básico determina que casi un $90 \%$ de la muestra corresponde a formas abiertas y que las formas simples superan a las compuestas casi en el mismo porcentaje. Entendemos como formas compuestas las vasijas en las que se pueden distinguir dos cuerpos, superior e inferior, que coinciden en un punto de unión, en el que la pared del recipiente cambia de dirección hasta llegar al fondo (Fernández 2012: 85, 94).

El grupo más destacado por su número son las fuentes, que constituyen algo más de la mitad del conjunto estudiado. Dentro de este, podemos encontrar dos variantes formales: las fuentes semiesféricas o de casquete esférico y las formas biseladas, con engrosamientos o pestañas en su borde, pero la mayor parte responden a un mismo patrón: vasijas muy aplanadas de gran tamaño (por lo general entre $300 \mathrm{~mm}$ y $500 \mathrm{~mm}$ de diámetro), de paredes gruesas y con tratamientos más cuidados en la superficie interior (fig. 10A).

El siguiente grupo son las ollas. Aunque se han documentado siete tipos distintos, el grueso lo componen las ollas ovoides simples (fig. 10C). Los cuencos, con el $9,5 \%$, se reparten entre forma semiesférica, semiesférica con el borde ligeramente entrante, de casquete esférico y uno de mayor profundidad (hondo). Los vasos suponen el 3.1\% del conjunto y se reparten entre formas carenadas y de perfil en S. Finalmente, la que tradicionalmente se interpreta como vajilla de almacenaje se reduce a cuatro orzas ovoides, que sobresalen claramente por su tamaño y volumen (fig. 10B). Todos los fragmentos de las orzas se encontraban en la fosa 8053 .

Con respecto al tratamiento de las superficies, se aprecia que se alisaron ambas caras en la mayoría de las fuentes y ollas, algo más de la mitad de los cuencos,

Tabla 1. Dataciones radiocarbónicas del Cerro de los Vientos.

\begin{tabular}{|c|c|c|c|c|c|c|c|c|c|c|c|}
\hline $\begin{array}{c}\text { Código } \\
\text { Laboratorio }\end{array}$ & Estructura/UE & Material & $\mathrm{BP}$ & \pm & $\% \mathrm{C}$ & $\% \mathrm{~N}$ & $\delta^{15} \mathrm{~N}$ & $\delta^{13} \mathrm{C}$ & $\mathrm{C}: \mathrm{N}$ & \multicolumn{2}{|c|}{ Calibración A.C. } \\
\hline ETH-74306 & $\begin{array}{c}\text { FS-8011 } \\
\text { UE 8012 }\end{array}$ & $\begin{array}{c}\text { Hueso humano } \\
\text { Tibia - adulto }\end{array}$ & 3107 & 20 & 43.4 & 15.2 & 8.7 & -18.9 & 3.3 & $1415-1315$ & $1430-1300$ \\
\hline ETH-74307 & $\begin{array}{c}\text { EST-VII } \\
\text { UE 8118 }\end{array}$ & $\begin{array}{c}\text { Hueso humano } \\
\text { Radio - adulto }\end{array}$ & 3125 & 20 & 28.3 & 10.0 & 8.7 & -18.7 & 3.2 & $1430-1325$ & $1440-1305$ \\
\hline
\end{tabular}


Figura 9. Porcentajes de las formas cerámicas estudiadas.

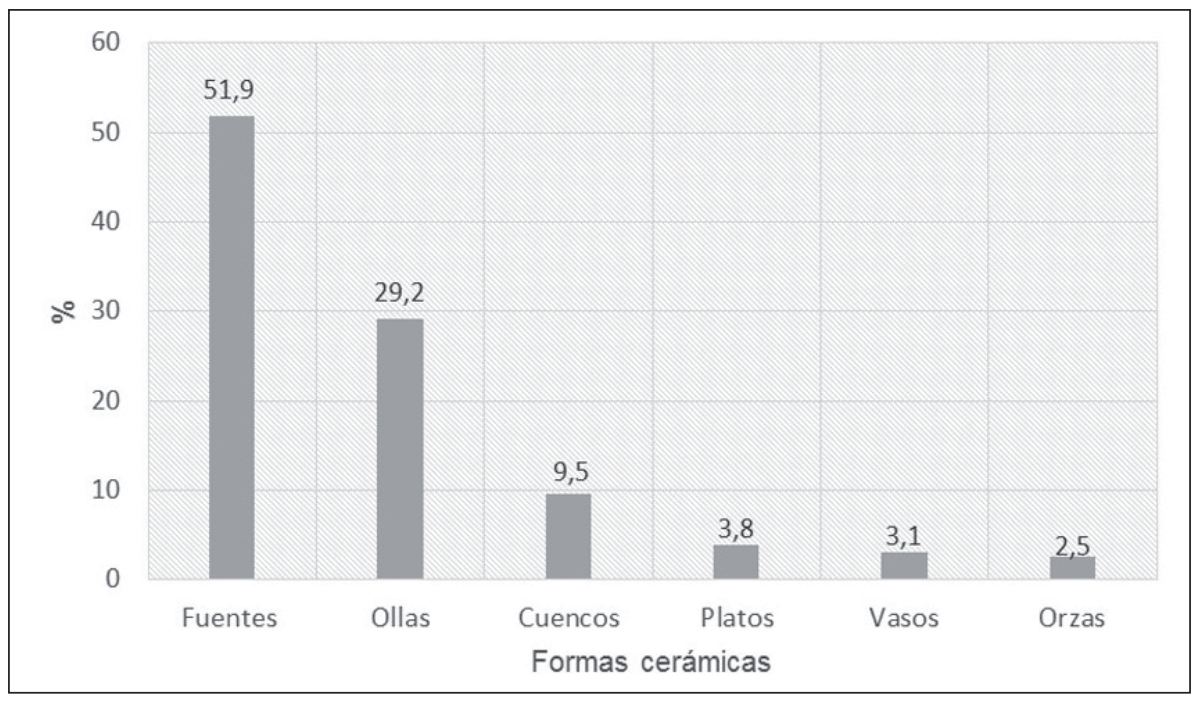

todos los platos y solo en un número reducido de los vasos. Por otra parte, el bruñido es menos abundante, destacándose especialmente en el caso de los vasos que lo presentan en la casi totalidad de los fragmentos. El pulido está poco representado y solo se ha registrado en un cuenco, un vaso carenado con carena media y una olla ovoide.

Respecto al proceso de elaboración o modelado, también se han documentado marcas de ensamblaje entre distintos cuerpos, marcas digitadas en determinadas zonas de las vasijas que muestran el recorrido de los dedos del alfarero/a mientras iba presionando para componerlas, e improntas que indican el uso de desgrasante vegetal. En los acabados también se evidenciaron rastros dejados por escobillas y espátulas, así como un fragmento cubierto por un engobe de color rojizo.

Cronológicamente, la tipología cerámica corresponde mayoritariamente a producciones de la Edad del Cobre, aunque con presencia de algunos fragmentos típicos del Bronce, especialmente de ollas compuestas con cuello.

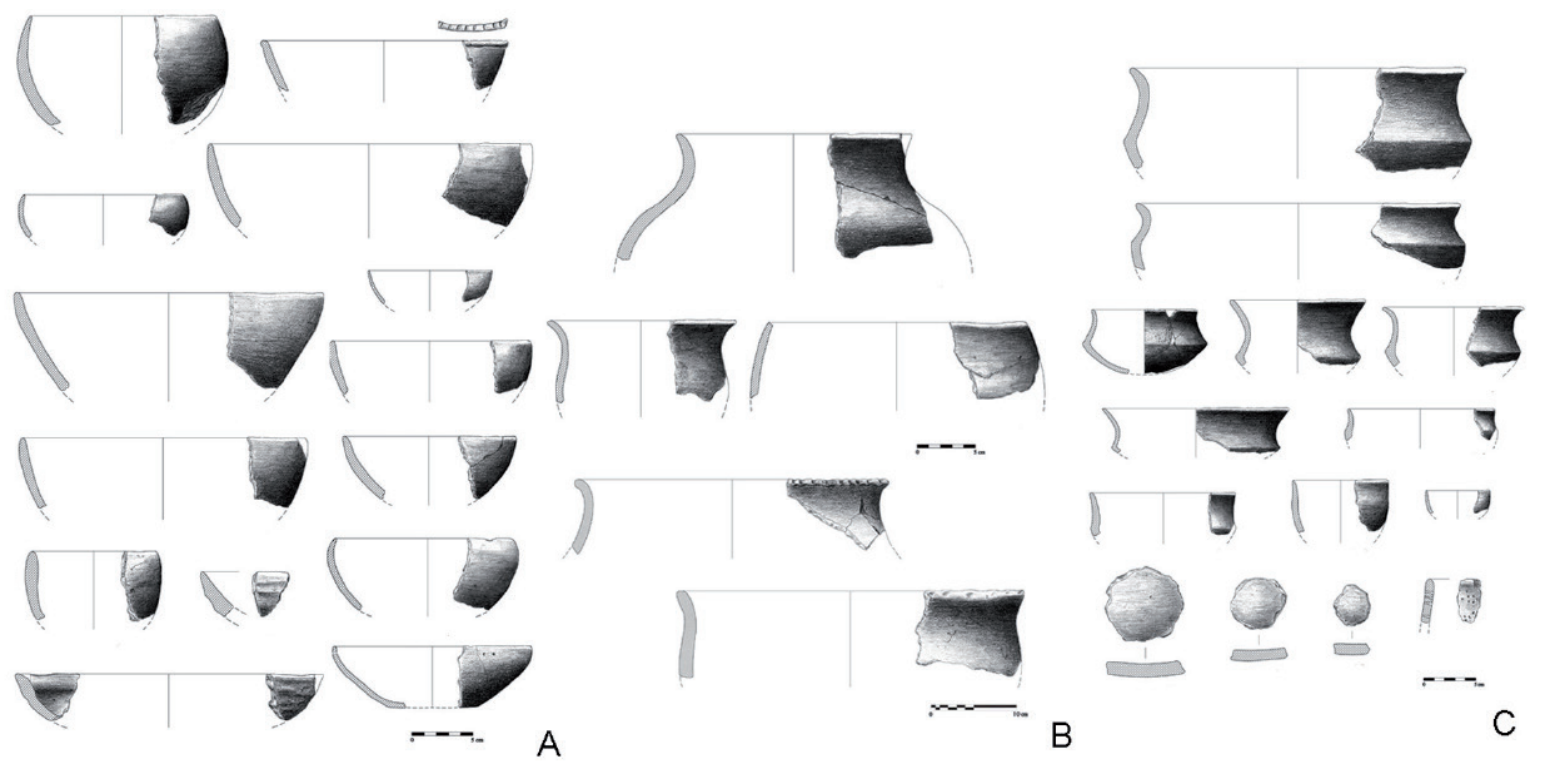

Figura 10. Formas cerámicas del Cerro de los Vientos. A) Fuentes, cuencos, platos y ollas ovoides, B) Ollas y orzas C) Formas carenadas, vasos, fichas recortadas. 
Tabla 2. Caracterización del material macrolítico por estructura y UE.

\begin{tabular}{|c|c|c|c|c|c|c|c|c|c|}
\hline Estructura & UE & Litología & $\begin{array}{l}\text { Largo } \\
(\mathrm{mm})\end{array}$ & $\begin{array}{l}\text { Ancho } \\
(\mathrm{mm})\end{array}$ & $\begin{array}{l}\text { Alto } \\
(\mathrm{mm})\end{array}$ & Tipo & $\begin{array}{c}\text { Tipo } \\
\text { actividad }\end{array}$ & $\begin{array}{l}\text { Superficie } \\
\text { activa }\end{array}$ & $\begin{array}{c}\text { Alteración } \\
\text { térmica }\end{array}$ \\
\hline \multirow{3}{*}{ EST-VII } & 8022 & Arenisca & 72 & 52 & 21 & Alisador & Activo & Plana pulida & - \\
\hline & 8022 & Caliza & - & - & - & Canto & Ecofacto & - & - \\
\hline & 8025 & Conglomerado & $300+$ & 230 & 82 & Molino & Pasivo & Irregular plana & - \\
\hline EST-III & 8005 & Conglomerado & $265+$ & 225 & 86 & Molino & Pasivo & Irregular plana & - \\
\hline Fosa 8077 & 8078 & Caliza & - & - & - & Canto & Ecofacto & - & $\mathrm{X}$ \\
\hline \multirow{3}{*}{$\begin{array}{c}\text { Fosa } 8020 \\
\text { (junto a EST-III) }\end{array}$} & 8021 & Arenisca & - & - & - & Canto & Ecofacto & - & - \\
\hline & 8021 & Granito & $96+$ & 122,5 & 42 & Mano & Activo & Irregular plana & - \\
\hline & 8021 & Conglomerado & $270+$ & $180+$ & 68 & Molino & Pasivo & Irregular plana & - \\
\hline \multirow{6}{*}{ FS-8011 } & 8113 & Arenisca & 62 & 43.5 & 16.5 & Afilador & Pasivo & Plana pulida & $\mathrm{X}$ \\
\hline & 8137 & Caliza & - & - & - & Canto & Ecofacto & - & $\mathrm{X}$ \\
\hline & 8113 & Caliza & - & - & - & Canto & Ecofacto & - & $\mathrm{X}$ \\
\hline & 8113 & Caliza & - & - & - & Canto & Ecofacto & - & $\mathrm{X}$ \\
\hline & 8113 & Caliza & - & - & - & Canto & Ecofacto & - & $\mathrm{X}$ \\
\hline & 8113 & Subvolcánica? & - & - & - & Canto & Ecofacto & - & $X$ \\
\hline
\end{tabular}

\subsection{Material lítico}

Por su parte, el material macrolítico de los rellenos fue estudiado considerando su clasificación morfotipológica, las huellas de uso sobre las superficies activas y las evidencias tecnológicas. En los criterios de medición se han considerado las siguientes medidas: eje longitudinal de la pieza (Largo); eje transversal (Ancho); altura máxima (Alto); y como variables cualitativas, la litología y el tipo de superficie activa. En todo el conjunto también se consideró la presencia de alteraciones térmicas.

La observación y toma de imágenes de las superficies activas se han realizado con una lupa binocular Leica EZ4 HD con una potencia de aumentos de 8x a 50x. Se ha seguido la metodología y la nomenclatura consensuadas para el estudio y descripción de las superficies activas (Adams et al. 2009). Los criterios para el análisis funcional se sustentan en la contrastación de las huellas de uso de la actividad que las produjo, con ejemplos etnográficos y experimentales (Delgado y Risch 2008, Delgado Raack 2008, Adams et al. 2009, Risch 2002, Hamon 2008).

El conjunto de materiales está constituido por seis piezas. Estas han sido divididas según el tipo de actividad con la que están relacionadas en dos grupos: elementos pasivos, como aquellos que se mantienen estáticos ante el trabajo que sobre ellos se efectúa, y útiles activos, con los que se desarrolla de una actividad directamente. Además de estas piezas se han analizado ocho ecofactos o elementos naturales sin huellas de uso, aunque algunos de ellos presentaban evidencias de alteraciones térmicas (tab. 2).

La presencia de estas rubefacciones en seis ecofactos y en un afilador se evidencia en toda la superficie de las piezas. Este tipo de alteraciones térmicas sobre el material macrolítico es común en yacimientos con estructuras negativas y ha sido documentado en varios contextos prehistóricos (Aranda Jiménez et al. 2012, García et al. 2014).

De los 6 útiles, tres son elementos de molturación, uno es una mano de moler y dos son abrasivos:

Útiles de molturación (fig.11: 1, 2 y 3). Las tres piezas (correspondientes a las EST-III, EST-VII y fosa 8020) poseen una forma oblonga y se hallan fracturadas en el extremo proximal del eje funcional de la pieza. Según las partes conservadas, el tamaño de los elementos debió ser de en torno a $300 \mathrm{~mm}$ de largo por 250 de ancho y 90 de alto. Las superficies activas son planas e irregulares, probablemente por el tipo de conglomerado en el que están elaboradas. La morfología y las 
Figura 11. Materiales macrolíticos del Cerro de los Vientos: 1, 2 y 3 . Molinos de molturación de cereal; 4 . Mano de moler; 5. Posible afilador de elementos metálicos; 6. Posible alisador de cerámica.

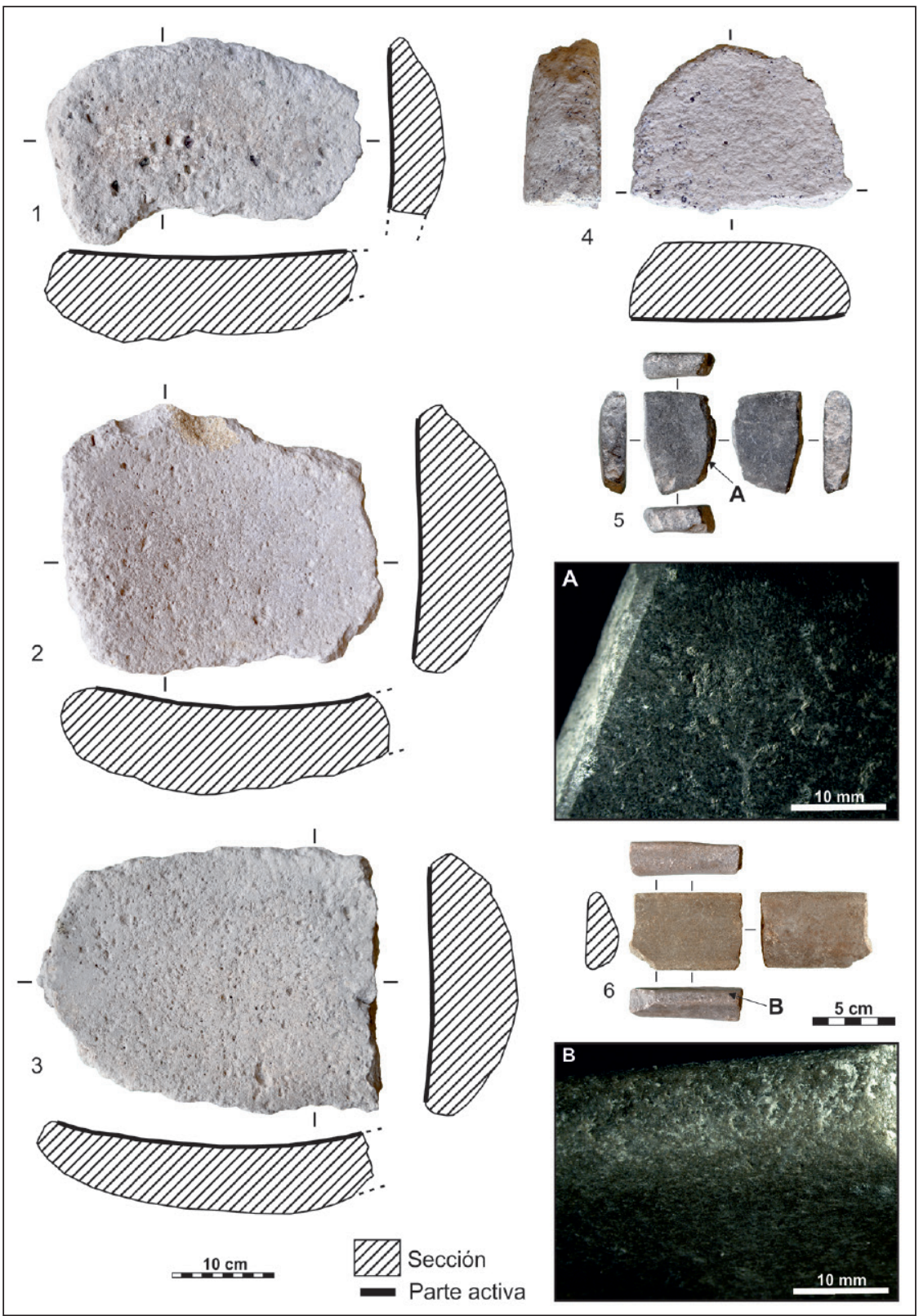

superficies activas indican el uso de estas piezas para la molturación. Los patrones de desgaste se relacionan con la molturación de cereales, como se puede deducir de la comparación de estas huellas con trabajos experimentales (Menasanch et al. 2002, Risch 2002, Dubreuil 2002, Zurro et al. 2005, Hamon 2008, Delgado Raack 2008, Verbaas y van Gjin 2008, Hamon y Plisson 2009, Bofil et al. 2013).

Mano de moler (fig.11: 4). Su forma es oblonga y se encuentra fracturada en el parte medial contrario a su eje activo. Sus medidas originales serían de unos 200 mm de largo (eje funcional) por 123 de ancho y 42 de alto. Esta pieza se usa en conjunción con los elementos de molturación para la molienda. El tipo de superficie activa es igual a la de los molinos recuperados. Precisamente la mano de moler y uno de los molinos aparecen asociados en la misma unidad estratigráfica (UE-8021).

Afilador (fig.11: 5). Se trata de una plaqueta de arenisca de forma rectangular. Las superficies activas son ambas caras y sus bordes. Presenta una nivelación de los granos en la superficie y zonas pulidas, brillantes y con estrías. Los bordes exteriores están redondeados 
formando planos de abrasión. Este tipo de trazas son concordantes con su uso como afilador, probablemente sobre metales si tenemos en cuenta sus zonas brillantes y planos de abrasión pulidos (fig.11: 5A) (Delgado y Rich 2008).

Alisador/bruñidor (fig.11: 6). Lo constituye un fragmento de canto alargado de arenisca. Las superficies activas se localizan en la cara plana de la pieza y en los bordes redondeados inferior y superior. Las huellas están formadas por un pulido de la superficie y estrías en los rebordes de la pieza (fig. 11: 6B). Este tipo de marcas se puede relacionar con la regularización de pastas para la elaboración de recipientes cerámicos.

El conjunto lítico se caracteriza por útiles fragmentados o en avanzado estado de uso. La cadena operativa de elaboración para los útiles de molturación es similar a la documentada en otros contextos de la Prehistoria Reciente en la península ibérica. La selección de los soportes naturales, así como la transformación de los mismos mediante talla exterior y abujardado de las superficies de trabajo son semejantes a las estudiadas en yacimientos del Neolítico Reciente (Aranda Jiménez et al. 2012), Edad del Cobre (Risch 2008) y Edad del Bronce (Risch 1995, Delgado-Raack 2008, Delgado-Raack y Risch 2016). De la misma forma, el uso de cantos rodados como abrasivos para afilar metales o el bruñido de cerámica es común en otros yacimientos de la Edad de Cobre (Delgado y Risch 2008, Risch 2008).

\subsection{Registro paleoambiental}

El estudio paleoambiental se ha basado en 11 muestras que procedían del foso interior $(n=6)$, fosa $8020(n=2)$ y EST-VI $(n=3)$. De acuerdo con el orden estratigráfico del foso interior, una de las muestras corresponde al Bronce (UE 8012) y cinco de ellas serían calcolíticas (UEs 8119, 8159, 8160, 8133 y 8124) (fig. 3). Por su parte, en la fosa 8020 se estudiaron dos muestras correspondientes con las UEs 8090 y 8092; mientras que de la EST-VI se analizaron tres muestras más (UEs 8045,8112 y 8149).

El tratamiento químico de las mismas se llevó a cabo en el Laboratorio de Arqueobiología del Instituto de Historia (CSIC, Madrid). El método usado para la extracción, tanto de los palinomorfos polínicos como no polínicos (Girard y Renault-Miskovsky 1969, Burjachs et al. 2003), consistió en un primer ataque al sedimento con $\mathrm{HCl}$ para la disolución de los carbonatos, seguido de $\mathrm{NaOH}$ para la eliminación de la materia orgánica, y finalmente con HF para la eliminación de los silicatos. El sedimento se trató además con 'licor de Thoulet' para la separación densimétrica de los microfósiles (Goeury y de Beaulieu 1979). La porción del sedimento que se obtuvo al final del proceso se conservó en gelatina de glicerina en tubo eppendorf. No se procedió a la tinción de la muestra por la posibilidad que existe de que enmascare la ornamentación de ciertos tipos polínicos. Tras el tratamiento y conservación, la muestra se montó en portaobjeto con cubreobjeto y posterior sellado con histolaque, para proceder al recuento de los distintos tipos polínicos y no polínicos al microscopio óptico. Los morfotipos polínicos siguen a Moore et al. (1991) y Reille (1992, 1995). Los microfósiles no polínicos se identificaron según López Sáez et al. (1998, 2000) y López Sáez y López Merino (2007).

Se ha considerado que una muestra es válida, estadísticamente hablando, cuando la denominada suma base polínica (S.B.P.) supera los 200 pólenes procedentes de plantas terrestres, albergando además una variedad taxonómica mínima de 20 tipos polínicos distintos (López Sáez et al. 2003). En el cálculo de los porcentajes se han excluido de la suma base polínica los taxa hidro-higrófilos y los microfósiles no polínicos, que se consideran de carácter local o extra-local, por lo que suelen estar sobrerrepresentados (López Sáez et al. 1998, 2000, 2003). Además se han excluido de esta a Cichorioideae, Cardueae y Aster tipo debido a su carácter antropozoógeno (Burjachs et al. 2003, López Sáez et al. 2013). El valor relativo de los palinomorfos excluidos se ha calculado respecto a la suma base polínica. El tratamiento de datos y representación gráfica se ha realizado con ayuda de los programas TILIA y TGview (Grimm 1992, Grimm 2004), junto con el programa de tratamiento de imagen COREL DRAW para el perfeccionamiento del histograma palinológico. En la validación de los datos obtenidos se han aceptado además las directrices estadísticas y tafonómicas expuestas en López Sáez et al. $(2003,2006)$ respecto a los contextos sedimentarios estudiados.

Los resultados reflejan algunos datos que permiten seguir diferenciando las dos etapas de ocupación del lugar. En la fosa 8020, localizada junto a la EST-II (fig. 12), las dos muestras estudiadas no resultaron estadísticamente significativas al presentar un contenido polínico inferior a 200 pólenes procedentes de plantas terrestres, lo que evidentemente limita cualquier tipo de información paleoambiental sobre ellas (López Sáez et al. 2003, López Sáez et al. 2013). No obstante, resulta interesante señalar que en ambas, la presencia de polen de cereal fue una constante y con valores relativamente 


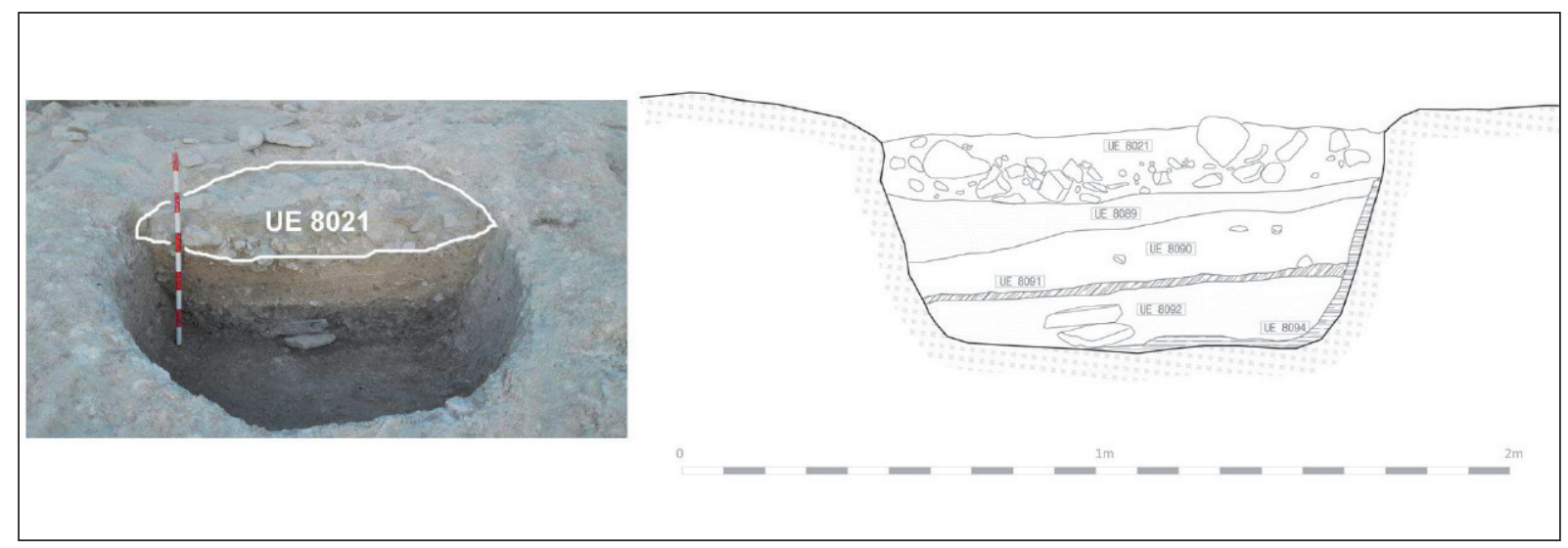

Figura 12. Sección de la Fosa 8020 con orientación S-N.

muy altos (más de la mitad de los pólenes identificados en las muestras de las UEs 8090 y 8092 correspondieron a este morfotipo). Esto lleva a considerar que tales valores elevados deben responder a un aporte indirecto de los pólenes junto con otras estructuras de los cereales como espigas, espiguillas, glumas, etc. (Robinson y Hubbard 1977). De hecho, en esta fosa 8020 aparecieron restos de molinos junto a una mano de molino (UE8021), algo que indicaría, probablemente, que en esta estructura o cerca de ella se realizaron actividades de molturación de cereales; de ahí la llegada indirecta de sus pólenes a los sedimentos que colmatan la estructura.

Las 9 muestras restantes de FS-8011 y EST-VI sí resultaron fértiles desde un punto de vista palinológico. En general, los espectros polínicos de las 5 muestras basales de FS-8011 (UEs 8119, 8159, 8160, 8133 y 8124), así como los de las tres de EST-VI (UEs 8045 , 8112 y 8149 ) son enormemente semejantes (fig. 13), lo que permite aceptar su contemporaneidad cronológica dentro del Calcolítico.

En general, el palinograma (fig. 13) muestra, durante el Calcolítico, una cobertura arbórea escasa, donde el porcentaje de polen arbóreo oscila entre el 14.7 y el $20.6 \%$, siendo el taxón más representado la encina (Quercus ilex) que en ningún caso sobrepasa el $17 \%$ (10.6-16.1\%) de la suma base polínica (S.B.P.). Los espectros polínicos de las muestras estudiadas reflejarían por tanto un paisaje sumamente abierto, deforestado, de encinar semi-adehesado (López Sáez et al. 2010). Este tipo de comunidad forestal, desde un punto de vista fitosociológico, debería asignarse a los encinares béticos, marianenses y araceno-pacenses basófilos mesomediterráneos del área (Paeonio coriaceae-Quercetum rotundifoliae). Además de la encina y Paeonia (0.5-1.5\%), localmente estos encinares quedan representados en el diagrama polínico por ciertos arbustos que normalmente forman parte de sus etapas degradativas, caso de los retamares o escobonales (Retama/Cytisus/Genista: 1.5-2.5\%), tomillares (Labiatae: 0-1.5\%), Crataegus monogyna (0-1.8\%) y Rhamnus (2.3-3.4\%). En particular, en el entorno inmediato del yacimiento, estos encinares estarían vinculados a su faciación más termófila y cálida, la cual en las áreas mesomediterráneas está enriquecida en acebuche (Olea europaea: 2.3-4\%), lentisco (Pistacia lentiscus: $4.5-7 \%$ ) y espárragos (Asparagus: 1.4$2.5 \%$ ). En algunas umbrías frescas de la comarca, en los piedemontes de sierras y en barrancos, es probable que se desarrollaran formaciones de quercíneas marcescentes, representadas en el diagrama polínico por el quegijo (Quercus faginea: 3.9-5.5\%).

Entre la flora herbácea, los palinomorfos predominantes serían las gramíneas (Poaceae) (33.7-40\%), cuyo elevado porcentaje refrendaría el carácter abierto y deforestado de las formaciones leñosas. El hecho más significativo, sin duda alguna, ha sido la identificación de polen de cereal (Cerealia) en algunas muestras de FS-8011, no así en EST-VI. En concreto, se ha identificado en las muestras de las UEs 8133 (4.1\%) y 8159 $(6 \%)$. Los valores de polen de cereal en ambas muestras son superiores al 3\%, lo que permitiría confirmar la existencia de cultivos agrícolas de cereal, en el entorno inmediato al yacimiento (López Sáez y López Merino 2005). Algunas herbáceas antrópico-nitrófilas, caso de Rumex acetosella (2.5-4.3\%), R. acetosa (2.9-4.3\%) y Convolvulus arvensis (1.4-2.5\%), probablemente estén relacionadas con dichos cultivos en forma de malas hierbas de estos (Behre 1981).

De la misma manera, ciertos palinomorfos indicativos de actividades de tipo pastoril, o de cierto tipo de 


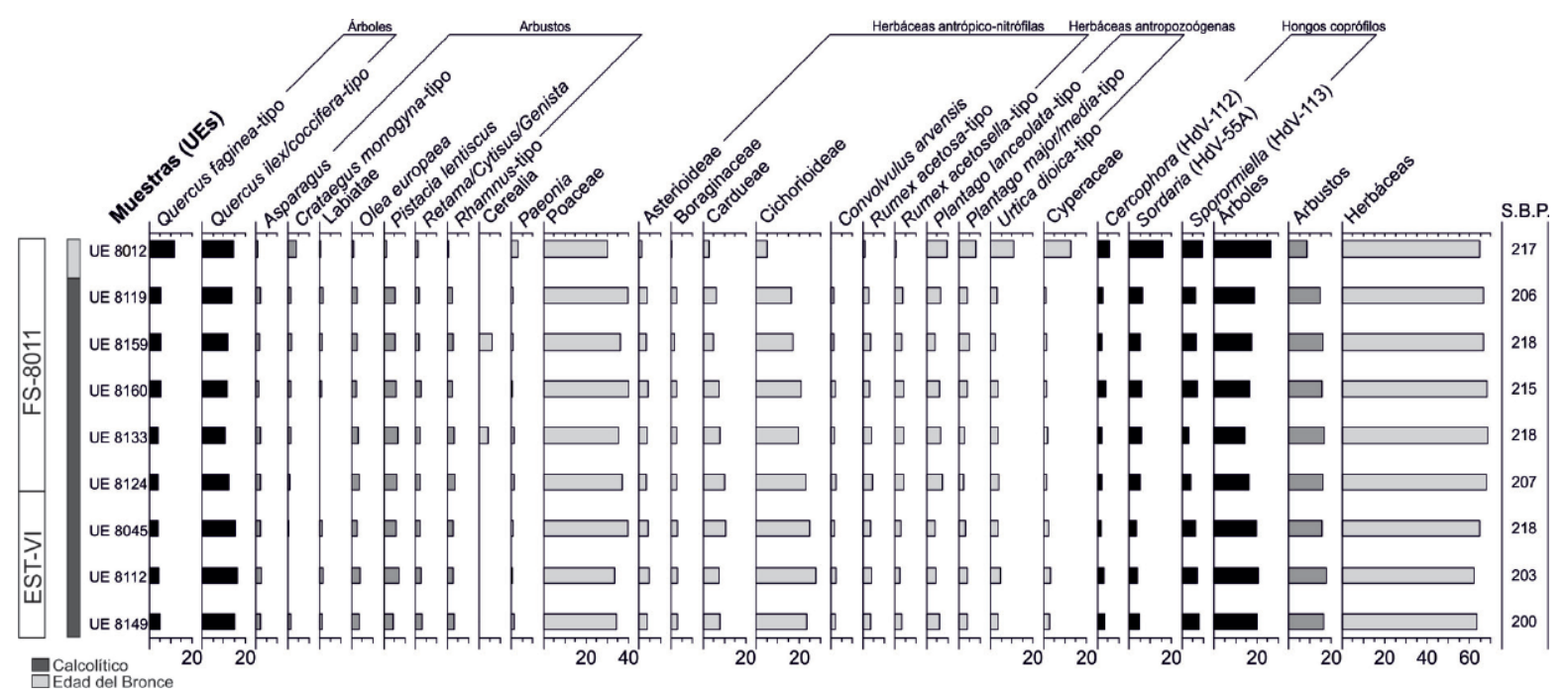

Figura 13. Histograma palinológico del Cerro de los Vientos.

presión derivada de la presencia de una cabaña ganadera en el entorno del sitio (herbáceas antropozoógenas), han sido identificados en las muestras asignadas al Calcolítico con valores relativamente altos. Estos son los casos de Plantago lanceolata (4.1-7.2\%), P. major/ media (2.4-5\%) y Urtica dioica (2.3-4.5\%). Lo mismo ocurre con ciertos hongos coprófilos como Sordaria (3.2-6.3\%), Sporormiella (3.2-8\%) y Cercophora (1.8$4.2 \%$ ), todo lo cual permitiría confirmar la importancia de la ganadería en el paisaje circundante al yacimiento (López Sáez y López Merino 2007).

De hecho, aunque agricultura y ganadería serían, posiblemente, los principales factores que definirían el paisaje hasta ahora descrito, no es menos cierto que en el palinograma aparecen toda una serie de indicadores polínicos de antropización, caso de Asterioideae (3.2$4.5 \%$ ), Boraginaceae (1.8-3.2\%), Cardueae (5-10.6\%) y Cichorioideae (16.5-28.1\%), que demostrarían la existencia de pastizales nitrófilos, de origen antrópico, fruto de una antropización ingente del paisaje.

Los porcentajes sumamente bajos de Cyperaceae (pastizales húmedos), inferiores al 3\%, así como la comentada preponderancia de elementos termófilos, probablemente serían significativos de un clima térmico y fundamentalmente árido, dentro de un proceso general de creciente aridificación en el sur de la península ibérica iniciado a mediados del IV milenio cal BC (Lillios et al. 2016).

A diferencia de las anteriores, la muestra procedente de la UE 8012 del FS-8011, cronológicamente situada en un momento avanzado de la Edad del Bronce, ofrece un espectro polínico completamente diferente (fig. 13). En ella, las formaciones caducifolias de Quercus faginea muestran valores más elevados $(12 \%)$, a la vez que se incrementan los porcentajes de pastizales húmedos de Cyperaceae $(12.4 \%)$. Estos hechos, indudablemente, serían el reflejo de un momento climático más húmedo y posiblemente también menos térmico, toda vez que se reducen los valores porcentuales de los elementos termófilos antes señalados (Olea europea y Asparagus $0.9 \%$, Pistacia lentiscus 1.4\%). En esta muestra no hay constancia de polen de cereal. En cambio, las evidencias de presión pastoral son ahora mucho más evidentes y elevadas que en momentos calcolíticos: se incrementan notablemente los hongos coprófilos (Sordaria 16.1\%, Sporormiella 9.7\%, Cercophora $6 \%$ ) así como las herbáceas antropozoógenas (Plantago lanceolata 9.7\%, Plantago major/media 7.8\%, Urtica dioica 10.6\%).

Estos hechos permitirían admitir la presencia in situ de una cabaña ganadera, probablemente estabulada, en el interior del yacimiento, con la consiguiente presión y alteración que esto supondría en la composición florística del entorno (López Sáez y López Merino 2007). No obstante, lo antes comentado no podría ser relacionado con una mayor ocupación o presión antrópica en el Cerro de los Vientos, ya que, a diferencia de lo anterior, las herbáceas antrópico-nitrófilas disminuyen bruscamente (Cichorioideae 5.1\%, Cardueae 2.8\%, Asterioideae $0.9 \%$, Boraginaceae $0.5 \%$, Rumex acetosa y Rumex acetosella $0.9 \%$ ). 


\section{DISCUSIÓN}

Los resultados de los análisis realizados permiten caracterizar el yacimiento en su contexto geográfico y cronológico. Morfológicamente, la presencia de dos fosos concéntricos diferentes reproduce rasgos conocidos en otros recintos de fosos peninsulares de similares dimensiones, como es el caso de Gózquez de Arriba (Díaz-del-Río 2004), por ejemplo. La trayectoria sinuosa de uno de sus fosos también encuentra paralelos en casos como los de Moreiros 2, Monte do Olival y Xancra en Portugal (Valera 2012, Valera 2013), o Venta del Rapa (Lechuga Chica et al. 2014), localizado a menos de $25 \mathrm{~km}$ del yacimiento.

Otro patrón conocido en este tipo de construcciones es la orientación astronómica que presentan muchas de las zonas de acceso al interior de los recintos. En este caso, la orientación al Este de las puertas de ambos recintos coincide con el orto solar durante los equinoccios de otoño y primavera. Este tipo de evidencias podrían ponerse en relación con la importancia que ciertos momentos del ciclo anual pudieron tener entre estas comunidades, tal y como se ha planteado en otros yacimientos de similares características como Xancra o Santa Vitória (Valera 2013).

Finalmente, en lo que respecta a la arquitectura del lugar, la existencia de un elevado número de estructuras tipo fosa también caracteriza a todos los recintos de fosos peninsulares. El Cerro de los Vientos destaca por una clara concentración de las mismas en los sectores este y noreste del yacimiento y por su completa ausencia en la zona central de lugar. Esta realidad podría demostrar su localización deliberada y, tal vez, la distinción de usos del espacio dentro de los diferentes recintos.

Los escasos restos de materiales orgánicos obtenidos en las excavaciones de los años 2014 y 2015, solo han permitido obtener dataciones que se corresponden con la fase más reciente de ocupación del yacimiento. Así lo demuestran las dataciones realizadas en el depósito más reciente del foso central y en la EST-VII. Estas corroboran la utilización del lugar en un momento muy tardío, con respecto a las dataciones conocidas para los recintos de fosos peninsulares. De hecho, en la región, solo se conocen dataciones tardías en rellenos de fosos en Marroquíes Bajos (Aranda Jiménez et al. 2016) y Venta del Rapa (Lechuga Chica et al. 2014), pero en ningún caso superan el primer cuarto del II milenio cal BC.

En este sentido, parece que este lugar estuvo ocupado durante la Edad del Bronce, aunque, como apunta la reconstrucción palinológica, con una ocupación menos importante que la existente durante la Edad del Cobre. Los datos polínicos apuntan a un cambio en las estrategias paleoeconómicas entre las comunidades del Calcolítico y del Bronce Tardío, estando caracterizado el primer periodo por unas bases económicas fundamentadas tanto en la agricultura como en la ganadería en un momento especialmente árido y cálido; mientras que en el segundo parece que la actividad ganadera cobró mayor importancia en un momento más húmedo y frío.

Por consiguiente, podemos afirmar que el recinto de fosos del Cerro de los Vientos encuentra sus inicios en la Edad del Cobre y presenta las características constructivas básicas compartidas por todos los yacimientos peninsulares de igual naturaleza. La posterior ocupación del espacio durante la Edad del Bronce pondría fin a la colmatación de algunas de sus estructuras, bajo unas nuevas formas de uso del lugar.

En lo referente a las actividades que en este espacio se desarrollaron, el análisis de los conjuntos cerámicos y líticos permite realizar algunas consideraciones.

En primer lugar, la caracterización de las formas cerámicas evidencia un mayor uso de recipientes abiertos, seguido de grandes ollas en las que previsiblemente se procesarían grandes cantidades de alimento. Una posibilidad que coincide con las características de la producción cerámica estudiada en otros recintos calcolíticos del sur peninsular (Lago et al. 1998, por ejemplo) y que podría indicar conductas de consumo de alimentos colectivas. Sorprende, sin embargo, que la presencia de recipientes que se relacionan tradicionalmente con el almacenaje (orzas) sea meramente testimonial.

En segundo lugar, el material lítico, aunque por el reducido número de piezas no permite extraer conclusiones a nivel estadístico, sí consigue acercarnos a una interpretación más amplia de las actividades que se llevaron a cabo en el yacimiento y las formas de colmatación de las estructuras.

Por una parte, la localización del material asociado a la molienda de cereales (molinos y mano) en los estratos finales de colmatación de ciertas estructuras, demuestra la producción y consumo de cereal, a la vez que refleja el tipo de depósitos realizados en el interior de las fosas y fosos.

Por otra parte, las alteraciones térmicas que se observan en los ecofactos y en el alisador pueden estar relacionadas con la reutilización de estos elementos como parte de hogares o quizás con la quema de estructuras construidas y tras ella la ocultación de sus restos en el interior de las fosas y fosos. 
Este último aspecto, la colmatación antrópica de las estructuras y el depósito de ciertos materiales en su interior, forma parte del debate acerca de la función y significado de este tipo de construcción prehistórica. Un debate que ha demostrado la importancia de la realización de estudios arqueológicos generales en estos yacimientos, con los que reconstruir las formas de vida, más o menos sedentarias, durante la Prehistoria reciente de la península ibérica.

En este sentido, el estudio del recinto de fosos del Cerro de los Vientos permite no solo conocer las características de un yacimiento calcolítico del sureste peninsular, sino también contribuir al estudio de un tipo de contexto complejo que requiere estudios interdisciplinares, bajo una mirada profundamente diacrónica y con matices regionales (Milesi García 2018: 436-441).

\section{CONCLUSIÓN}

El yacimiento prehistórico del Cerro de los Vientos se presenta como un nuevo recinto de fosos calcolítico del sur peninsular. Los resultados de su estudio proponen una biografía extensa para el yacimiento que cuenta con, al menos, dos períodos de ocupación a lo largo de la Prehistoria reciente.

Durante el III milenio cal BC, se habrían llevado a cabo las construcciones de los fosos y las principales estructuras que componen los dos recintos que lo conforman. En este mismo período también se habría producido la colmatación parcial o completa de las construcciones, siguiendo las mismas dinámicas que se observan en contextos arqueológicos similares.

Finalmente, en el tercer cuarto del II milenio cal $\mathrm{BC}$, parece haberse producido la remodelación del espacio a través de la construcción de nuevas estructuras, junto con la completa amortización de su foso interno. Esta segunda fase de ocupación, ya sin recintos, evidencia los cambios en el paisaje y las actividades desarrolladas por las nuevas comunidades del Bronce.

\section{Apoyo financiero}

El presente trabajo forma parte del proyecto de investigación "Innovación, hibridación y resistencia cultural. Las sociedades de III y II milenios cal BC en el sur de la Península Ibérica" (HAR2017-82932-P). Ministerio de Economía, Industria y Competitividad.

\section{Agradecimientos}

El presente trabajo forma parte del proyecto de investigación "Innovación, hibridación y resistencia cultural. Las sociedades de III y II milenios cal BC en el sur de la Península Ibérica" (HAR2017-82932-P). Ministerio de Economía, Industria y Competitividad.

Agradecemos el acceso a materiales e informe de excavación para realizar los estudios y figuras que se presentan en este trabajo a Gespad Al-andalus s.l.u., en especial a Ángel Rodríguez Aguilera, José Ma García-Consuegra Flores y Julia Rodríguez Aguilera.

Queremos igualmente agradecer a los evaluadores anónimos sus comentarios y sugerencias que han ayudado a mejorar el presente trabajo.

En el momento de la realización del estudio palinológico aquí presentado, Sebastián Pérez Díaz disfrutaba de un contrato post-doctoral Juan de la Cierva, adscrito al Instituto de Historia (Centro de Ciencias Humanas y Sociales, CSIC).

\section{BIBLIOGRAFÍA}

Adams, J.; Delgado, S.; Dubreuil, L.; Hamon, C.; Plisson, H. y Risch, R. (2009): "Functional analysis of macro-lithic artefacts: A focus on working surfaces”, en F. Sternke, L. Eigeland y L.J. Costa (eds.), Non-Flint raw material use in Prehistory. Old prejudices and new directions. BAR International Series 1939: 43-66. Londres, BAR publishing.

Aranda Jiménez, G. (2001): El análisis de la relación forma-contenido de los conjuntos cerámicos del yacimiento arqueológico del Cerro de la Encina (Granada, España), British Archaeological Reports. International Series 927. Oxford, Archaeopress.

Aranda Jiménez, G.; Cámalich Massieu, M.D.; Martín Socas, D.; Morgado, A.; Martínez-Sevilla, F.; Lozano Rodríguez, J.A.; Rodríguez Rodríguez, A.; Mancilla Cabello, M.I. y Román Punzón, J. (2012): La Loma (Íllora, Granada) Un yacimiento de fosas del VI-IV milenios cal BC. Monografías de Arqueología. Sevilla, Junta de Andalucía, Consejería de Cultura.

Aranda Jiménez, G.; Lozano Medina, A.; Escudero Carrillo, J.; Sánchez Romero, M.; Alarcón García, E.; Fernández Martín, S.; Díaz-Zorita Bonilla, M. y Barba Colmenero, V. (2016): “Cronología y temporalidad de los recintos de fosos prehistóricos: el caso de Marroquíes Bajos (Jaén). Trabajos de Prehistoria 73 (2): 231-250. https://doi.org/10.3989/ tp.2016.12171.

ISSN: 1133-4525 ISSN-e: 2255-3924 https://dx.doi.org/10.12795/spal.2020.i29.15 
Aranda Jiménez, G.; Lozano Medina, A.; Camalich Massieu, M.D.; Martín Socas, D.; Rodríguez Santos, F.J.; Trujillo Mederos, A.; Santana Cabrera, J.; Nonza-Micaellie, A. y Clop García X. (2017): "La cronología radiocarbónica de las primeras manifestaciones megalíticas en el sureste de la Península Ibérica: las necrópolis de Las Churuletas, La Atalaya y Llano del Jautón (Purchena, Almería)". Trabajos de Prehistoria 74 (2): 257-277. https://doi. org/10.3989/tp.2017.12194

Aranda Jiménez, G.; Lozano Medina, A.; Sánchez Romero, M.; Díaz-Zorita Bonilla, M. y Bocherens H. (2018): "The chronology of the megalithic funerary practices in South-eastern Iberia: the necropolis of Panoría (Granada, Spain)". Radiocarbon 60 (1): 1-19. https://doi.org/10.1017/RDC.2017.96

Aranda Jiménez, G.; Díaz-Zorita Bonilla, M.; Hamilton, D.; Milesi, L. y Sánchez Romero M. (2020): “The radiocarbon chronology and temporality of the megalithic cemetery of Los Millares (Almería, Spain)". Archaeological and Anthropological Sciences 12, https://doi.org/10.1007/s12520-020-01057-7

Balsera, V.; Bernabeu Aubán, J.; Costa-Caramé, M.; Díaz-del-Río, P.; García Sanjuán y Pardo, S. (2015): "The Radiocarbon Chronology of Southern Spain's Late Prehistory (5600-1000 cal BC): a comparative review". Oxford Journal of Archaeology 34 (2): 139-156. https://doi.org/10.1111/ojoa.12053.

Behre, K.E. (1981): "The interpretation of anthropogenic indicators in pollen diagrams". Pollen et Spores 23: 225-245.

Blasco, C.; Delibes, G.; Baena, J.; Liesau, C. y Ríos, P. (2007): "El poblado calcolítico de Camino de las Yeseras (San Fernando de Henares, Madrid): un escenario favorable para el estudio de la incidencia campaniforme en el interior peninsular". Trabajos de Prehistoria 64 (1): 151-163. https://doi. org/10.3989/tp.2007.v64.i1.99.

Bocherens, H.; Billiou, D.; Patou-Mathis, P.; Bonjean, D.; Otte, M. y Mariotti, A. (1997): "Paleobiological implications of the isotopic signatures (13C, $15 \mathrm{~N})$ of fossil mammal collagen in Scladina cave (Sclayn, Belgium)". Quaternary Research 48: 370380. https://doi.org/10.1006/qres.1997.1927.

Bofill, M.; Procopiou, H.; Vargiolu, R. y Zahouani, H. (2013): "Use-wear analysis of near eastern prehistoric grinding stones", en P.C. Anderson, C. Cheval y A. Durand (eds.), Regards croisés sur les outils liés au travail des végétaux: 225-242. Paris, Association pour la Promotion et la Diffusion des Connaissances Archéologiques.
Bronk Ramsey, C. (2009): "Bayesian Analysis of radiocarbon dates". Radiocarbon 51(1): 37-360. https:// doi.org/10.1017/S0033822200033865.

Burjachs, F.; López Sáez, J.A. e Iriarte, M.J. (2003): "Metodología Arqueopalinológica", en R. Buxó y R. Piqué (dirs.), La recogida de muestras en Arqueobotánica: objetivos y propuestas metodológicas. La gestión de los recursos vegetales y la transformación del paleopaisaje en el Mediterráneo occidental: 11-18. Barcelona, Museu d'Arqueologia de Catalunya.

Delgado Raack, S. (2008): Prácticas económicas y gestión social de recursos (macro)líticos en la prehistoria reciente (III-I milenios AC) del Mediterráneo occidental. Tesis doctoral, Universitat Autònoma de Barcelona. https://hdl.handle.net/10803/5528 $(19 / 06 / 2020)$

Delgado, S. y Risch, R. (2008): "Lithic perspectives on metallurgy: an example from Copper and Bronze Age south-east Iberia", en L. Longo y N. Skakun (eds.), Prehistoric technology 40 years later: Funcional studies and Russian Legacy. BAR International Series 1783: 235-252. Oxford, Archaeopress.

Delgado-Raack, S. y Risch, R. (2016): "Bronze Age cereal processing in Southern Iberia: A material approach to the production and use of grinding equipment". Journal of Lithic Studies (2016) 3: 125-145. https://doi.org/10.2218/jls.v3i3.1650

Delibes de Castro, G. (2001). "Del Bronce al Hierro en el valle medio del Duero: una valoración del límite Cogotas I-Soto de Medinilla a partir de las manifestaciones de culto". Zephyrvs 53: 293-309.

Delibes de Castro, G.; García García, M.; Del Olmo, M. y Santiago Pardo, J. (2014): Recintos de fosos calcolíticos del Valle Medio del Duero. Arqueología aérea y espacial. Studia Archaeologica 100. Valladolid, Universidad de Valladolid.

DeNiro, M.J. y Epstein, S. (1981). "Influence of diet on the distribution of nitrogen isotopes in animals". Geochim Cosmochim Acta 45: 341-351.

Díaz-del-Río, P. (2003): "Recintos de fosos del III milenio AC en la Meseta peninsular". Trabajos de Prehistoria 60 (2): 61-78. https://doi.org/10.3989/ tp.2003.v60.i2.81.

Díaz-del-Río, P. (2004): “Copper Age Ditched Enclosures in Central Iberia”. Oxford Journal of Archaeology 23 (2): 107-121. https://doi.org/10.1111/ j.1468-0092.2004.00204.x

Díaz-Zorita Bonilla, M.; Beck, J.; Bocherens, H.y Díaz-del-Río, P. (2018): "Isotopic evidence for mobility at large-scale human aggregations in Copper 
Age Iberia: the mega-site of Marroquíes". Antiquity 92 (364): 991-1007. https://doi.org/10.15184/ aqy.2018.33.

Díaz-Zorita Bonilla, M; Beck, J.; Aranda Jiménez, G.; Milesi García, L.; Sánchez Romero, M.; Lozano Mediona, A.; Escudero Carrillo, J.; Knipper, C. (2020): “ The Deposition of Human Remains Inside Chalcolithic Ditched Enclosures: Ditch 5 at Marroquíes (Jaén, Spain) ". European Journal of Archaeology: 1-26 doi: https://doi.org/ 10.1017/ eaa. 2020.4

Dubreuil, L. (2002): Etude fonctionnelle des outils de broyage natoufiens : nouvelles perspectives sur l'émergence de l'agriculture au Proche-Orient. Tesis doctoral, Université de Bordeaux. http://www. theses.fr/2002BOR12546 (19/06/2020)

Escudero Carrillo, J.; Díaz-Zorita Bonilla, M.; Bartelheim, M. y García Sanjuán, L. (2017): “Chalcolithic Enclosures in the Lower Guadalquivir Basin La Loma Del Real Tesoro (Carmona, Seville, Spain) and Its Resources", en M. Bartelheim, P. Bueno Ramírez y M. Kunst (eds), Key resources and sociocultural developments in the Iberian chalcolithic: 257-272. Tübingen, Tübingen Library Publishing.

Fernández Gómez, F. y Oliva Alonso, D. (1986): “Valencina de la Concepción (Sevilla). Excavaciones de urgencia". Revista de Arqueología 58: 19-23.

Fernández Martín, S. (2012): Clasificación tipológica de la cerámica del yacimiento de la Edad del Bronce de la Motilla del Azuer (Ciudad Real, España). BAR International Series 2377. Oxford, British Archaeological Reports.

García García, M. (2013): "Las Pozas (Casaseca de las Chanas, Zamora): dos nuevos recintos de fosos calcolíticos en el Valle del Duero". Trabajos de Prehistoria 70: 175-184. https://doi.org/10.3989/ tp.2013.12108.

García González, D. G.; Morgado, A.; Martínez-Sevilla, F.; Sánchez, R. M. M.; Fernández, S.; Martín, M. G. R.; y Bandera, P.S. (2014): "Intervención en el Cerro de Marimacho (Antequera, Málaga): primeras evidencias de la existencia de un foso". Menga: revista de Prehistoria de Andalucía 5:247-257.

García Sanjuán, L.; Vargas Jiménez, J.M.; Cáceres Puro, L.M.; Costa Caramé, M.E.; Díaz-Guardamino Uribe, M.; Díaz-Zorita Bonilla, M.; Fernández Flores, A.; Hurtado Perez, V.; López Aldana, P.M.; Méndez Izquierdo, E.; Pajuelo Pando, A.; Rodríguez Vidal, J.; Wheatley, D.; Bronk Ramsey, C.; Delgado Huertas, A.; Dunbar, E.; Mora González, A.; Bayliss, A.; Beavan, N.; Hamilton, D. y
Whittle, A. (2018): “Assembling the Dead, Gathering the Living: Radiocarbon Dating and Bayesian Modelling for Copper Age Valencina de la Concepción (Seville,Spain)". Journal of World Prehistory 31 :179-313. https://doi.org//10.1007/s10963 018 91142.

Girard, M. y Renault-Miskovsky, J. (1969): "Nouvelles techniques de préparation en palynologie appliquées à trois sédiments du Quaternaire final de l'Abri Cornille'. Bulletin de l'Association française pour l'Etude du Quaternaire 1969 (4): 275-284.

Goeury, C. y Beaulieu, J.L. de (1979): “À propos de la concentration du pollen à l'aide de la liqueur de Thoulet dans le sédiments minéraux". Pollen et Spores 21: 239-251.

Grimm, E.C. (1992): Tilia, version 2. Springfield. IL 62703. Springfield, Illinois State Museum, Research and Collection Center.

Grimm, E.C. (2004): TGView. Springfield, Illinois State Museum.

Hamon, C. (2008): "Funtional analysis of stone grinding and polishing tools from the earliest Neolithic of north-western Europe". Journal of Archaeological Science 35: 1502-1520. https://doi. org/10.1016/j.jas.2007.10.017.

Hamon, C. y Plisson, H. (2009): "Functional analysis of grinding stones: The blind test", en L. Longo y N. Skakun (eds.), "Prehistoric Technology" 40 years later: Functional studies and the Russian legacy: 29-38. Verona, Museo Civico di Verona \& Universita degli Studi di Verona.

Hurtado, V. (1986): "El Calcolítico en la cuenca media del Guadiana y la necrópolis de La Pijotilla”, en G. Muñoz Carballo (ed.), Actas de la Mesa Redonda sobre Megalitismo Peninsular: 51-77. Madrid, Asociación de Amigos de la Arqueología.

Jiménez-Jáimez, V. (2015): “The Unsuspected Circles. On the Late Recognition of Southern Iberian Neolithic and Chalcolithic Ditched Enclosures". Proceedings of the Prehistoric Society 8: 179-198. https:// doi.org/10.1017/ppr.2015.5.

Lago, M.; Duarte, C.; Valera, A.; Albergaria, J.; Almeida, F. y Carvalho, A. (1998): "Povoado dos Perdigões (Reguengos de Mosaraz): dados preliminares dos trabalhos arqueológicos realizados em 1997". Revista portuguesa de Arqueología 1(1): 45-152.

Lechuga Chica, M. A.; Soto Civantos, M. y Rodríguez-Ariza, M. O. (2014): "El poblado calcolítico "Venta del Rapa" (finales III milenio Cal. BC.), Mancha Real, Jaén. Un recinto de fosos entre las 
estribaciones de Sierra Mágina y el Alto Guadalquivir". Trabajos de Prehistoria 71 (2): 353-367. https://doi.org/10.3989/tp.2014.12139.

Lizcano, R.; Gómez, E.; Cámara, J.A.; Aguayo, M.; Araque, D.; Bellido, I.; Contreras, I.; Hernández, M.; Izquierdo, M. y Ruiz, J. (1993): “1ª Campaña de excavación de urgencia en el pabellón polideportivo de Martos (Jaén)". Anuario Arqueológico de Andalucía 1991, III Actividades de Urgencia: 278-291.

López Sáez, J.A. y López Merino, L. (2005): “Precisiones metodológicas acerca de los indicios paleopalinológicos de agricultura en la Prehistoria de la Península Ibérica". Portugalia 26: 53-64.

López Sáez, J.A. y López Merino, L. (2007): “Coprophilous fungi as a source of information of anthropic activities during the Prehistory in the Amblés Valley (Ávila, Spain): the archaeopalynological record". Revista Española de Micropaleontología 39 (1-2): 103-116.

López Sáez, J.A.; van Geel, B.; Farbos-Texier, S. y Diot, M.F. (1998): "Remarques paléoécologiques à propos de quelques palynomorphes non-polliniques provenant de sédiments quaternaires en France". Revue de Paléobiologie 17 (2): 445-459.

López Sáez, J.A.; van Geel, B. y Martín Sánchez, M. (2000): “Aplicación de los microfósiles no polínicos en Palinología Arqueológica", en V. Oliveira Jorge (coord. ed.), Contributos das Ciências e das Technologias para a Arqueologia da Península Ibérica. Actas do $3^{\circ}$ Congresso de Arqueologia Peninsular, vol. IX: 11-20. Vila-Real (1999), Oporto, ADECAP.

López Sáez, J.A.; López García, P. y Burjachs Casas, F. (2003): “Arqueopalinología: Síntesis Crítica". Polen 12: 5-35.

López Sáez, J.A.; Burjachs Casas, F.; López García, P. y López Merino, L. (2006): “Algunas precisiones sobre el muestreo e interpretación de los datos en Arqueopalinología". Polen 15: 17-29.

López Sáez, J.A.; Alba Sánchez, F.; López Merino, L. y Pérez Díaz, S. (2010): "Modern pollen analysis: a reliable tool for discriminating Quercus rotundifolia communities in Central Spain". Phytocoenologia 40 (1): 57-72. https://doi.org/10.1127/0340269X/2010/0040-0430.

López Sáez, J.A.; Iriarte Chiapusso, M.J. y Burjachs i Casas, F. (2013): “Arqueopalinología”, en M. García-Diez y L. Zapata (eds.), Métodos y técnicas de análisis y estudio en Arqueología Prehistórica. De lo técnico a la reconstrucción de los grupos humanos: 273-290. Vitoria, Universidad del País Vasco.

Márquez Romero, J.E. (2001): "De los 'campos de silos' a los 'agujeros negros': sobre pozos, depósitos y zanjas en la Prehistoria Reciente del Sur de la Península Ibérica”. Spal 10: 207-220. https://doi. org/10.12795/SPAL.2001.I10.14.

Márquez Romero, J.E. (2002): "Megalitismo, agricultura y complejidad social: algunas consideraciones”. Baética: Estudios de arte, geografia e historia 24: 193-222.

Márquez Romero, J.E y Jiménez Jáimez, V. (2010): Recintos de Fosos. Genealogía y significado de una tradición en la Prehistoria del suroeste de la Península Ibérica (IV-III milenios AC). Málaga, Servicio de Publicaciones e Intercambio Científico, Universidad de Málaga.

Márquez Romero, J. E. y Jiménez Jáimez, V. (2013): "Monumental ditched enclosures in southern Iberia (fourth-third millenia BC)". Antiquity 87: 447-460. https://doi.org/10.1017/S0003598X0004905X.

Márquez Romero, J. E.; Valera, A. C.; Becker, H.; Jiménez Jáimez, V. y Suárez Padilla, J. (2011): “El Complexo Arqueológico dos Perdigōes (Reguengos de Monsaraz, Portugal). Prospecciones Geofísicas - Campañas 2008-2009". Trabajos de Prehistoria 68(1): 175-186. https://doi.org/10.3989/ tp.2011.11065.

Martínez Calvo, M.V.; López Jiménez, O. y Moreno García, E. (2014): "El poblado calcolítico de El Juncal (Getafe, Madrid)", en Actas de las novenas jornadas de patrimonio Arqueológico en la Comunidad de Madrid: 149-158. Madrid (2012), Madrid, Comunidad de Madrid, Consejería de Cultura y Deportes, Dirección General de Patrimonio Histórico.

Menasanch, M.; Risch, R. y Soldevilla J.A. (2002): "Las tecnologías del procesado de cereal en el sudeste de la Península Ibérica durante el III y II milenio ANE", en R. Treuil y H. Procopiou (eds.), Moudre et Broyer: 81-110. París, Publication du C.T.H.S.

Milesi García, L.B. (2018): Lugares de agregación en la Prehistoria desde una perspectiva etnográfica. Los recintos de fosos como caso de estudio. Tesis doctoral, Universidad de Granada. http://hdl. handle.net/10481/54431(19/06/2020)

Milesi, L.; Márquez-Romero, J.E.; Suárez-Padilla, J.; Caro Herrero, J.L. (2019): “Arquitectura monumental final (2500-2250 AC) en el yacimiento de Perdigões (Portugal). Aspectos formales y cronológicos a partir del estudio de Foso 2". Trabajos de 
Prehistoria 76 (1):161-176. https://doi.org/10.3989/ tp.2019.12232.

Moore, P.D.; Webb, J.A. y Collinson, M.E. (1991): Pollen analysis. 2nd edition. Londres, Blackwell Scientific Publications.

Reille, M. (1992): Pollen et Spores d'Europe et d'Afrique du Nord. Marsella, Laboratoire de Botanique Historique et Palynologie.

Reille, M. (1995): Pollen et Spores d'Europe et d'Afrique du Nord. Supplement 1. Marsella, Laboratoire de Botanique Historique et Palynologie.

Reimer, P. J.; Bard, E.; Bayliss, A.; Beck, J. W.; Blackwell, P. G.; Bronk Ramsey, C.; Grootes, P. M.; Guilderson, T. P.; Haflidason, H.; Hajdas, I.; Hattž, C.; Heaton, T. J.; Hoffmann, D. L.; Hogg, A. G.; Hughen, K. A.; Kaiser, K. F.; Kromer, B.; Manning, S. W.; Niu, M.; Reimer, R. W.; Richards, D. A.; Scott, E. M.; Southon, J. R.; Staff, R. A.; Turney, C. S. M. y Van der Plicht, J. (2013): "IntCal13 and Marine13 Radiocarbon Age Calibration Curves 0-50,000 Years cal BP”. Radiocarbon 55 (4): 18691887. https://doi.org/10.2458/azu_js_rc.55.16947.

Risch, R. (1995): Recursos Naturales y Sistemas de Producción en el Sudeste de la Península Ibérica Entre 3000 y 1000 ANE. Tesis doctoral, Universitat Autònoma de Barcelona, Bellaterra. https://hdl. handle.net/10803/5524 (19/06/2020)

Risch, R. (2002): Recursos Naturales, Medios de Producción y Explotación Social. Un Análisis Económico de la Industria Lítica de Fuente Álamo (Almería), 2250-1400 Antes de Nuestra Era. Iberia Archaeologica 3. Maguncia, Philipp von Zabern.

Risch, R. (2008): "Grain processing technologies and economic organisation: a case study from the southeast of the Iberian Peninsula during the Copper Age". The Arkeotek Journal 2(2): 1-20.

Robinson, M. y Hubbard, R.N.L.B. (1977): “The transport of pollen in the bracts of hulled cereal". Journal of Archaeological Science 4: 197-199.
Stuiver, M. A. y Polach, H. A. (1977): "Reporting the rate of 14C data". Radiocarbon 19: 355-363.

Valera, A. C. y Filipe, I. (2004): “O povoado do Porto Torrão (Ferrerira do Alentejo): novos dados e novas problemáticas no contexto da calcolitização do $\mathrm{Su}-$ doeste peninsular". ERA Arqueologia 6: 28-61.

Valera, A.C. (2012): "Fossos sinuosos na Pré-História Recente do Sul de Portugal: ensaio de análise crítica", en Actas do V Encontro de Arqueologia do Sudoeste Peninsular: 25-38. Almôdovar (2011), Município de Almodôvar.

Valera, A.C. (2013): "Recintos de Fossos da Pré-Historia Recente em Portugal. Investigação, discursos, salvaguarda e divulgação", en Grandes Projectos da Arqueologia Portuguesa. Al-madan II Serie 18: 93110. Almada, Centro de Arqueologia de Almada.

Verbaas, A. y van Gijn, A. (2008): "Querns and other hard stone tools from Geleen-Janskamperveld", en P. Van de Velde (ed.), Excavations at Geleen-Janskamperveld 1990/1991: 191-204. Leiden, University of Leiden.

Zafra de la Torre, N.; Hornos Mata, F. y Castro López, M. (1999): "Una macro-aldea en el origen del modo de vida campesino: Marroquíes Bajos (Jaén) c. 25002000 cal. ANE". Trabajos de Prehistoria 56(1): 77102. https://doi.org/10.3989/tp.1999.v56.i1.291.

Žalaitea, I.; Maurera, A.F.; Grimes,V.; Silva, A.M.; Ribeiroh, S.; Santos, J.F.; Barrocas Dias, C. y Valera, A.C. (2018): "Diet and mobility of fauna from Late Neolithic-Chalcolithic site of Perdigões, Portugal". Journal of Archaeological Science: Reports 19: 674-685. https://doi.org/10.1016/j.jasrep.2018.03.033.

Zurro, D.; Risch, R., y Clemente-Conte, I. (2005): "Analysis of an archaeological grinding tool: What to do with archaeological artefacts", en X. Terradas (ed.), Lithic toolkits in ethoarchaeological contexts. BAR International Series 1370:57-64. Oxford, BAR publishing. 